\title{
Aerosol charging state at an urban site: new analytical approach and implications for ion-induced nucleation
}

\author{
S. Gagné ${ }^{1, *}$, J. Leppä2 ${ }^{2}$ T. Petäjä ${ }^{1}$, M. J. McGrath ${ }^{1, * *}$, M. Vana ${ }^{1,3}$, V.-M. Kerminen ${ }^{2}$, L. Laakso ${ }^{1,2,4}$, and M. Kulmala \\ ${ }^{1}$ Department of Physics, University of Helsinki, P.O. Box 64, 00014 Helsinki, Finland \\ ${ }^{2}$ Finnish Meteorological Institute, Climate Change, P.O. Box 503, 00101 Helsinki, Finland \\ ${ }^{3}$ Institute of Physics, University of Tartu, Ülikooli 18, 50090 Tartu, Estonia \\ ${ }^{4}$ School of Physical and Chemical Sciences, North-West University, Private Bag x6001, Potchefstroom 2520, South Africa \\ * now at: Dept. of Physics and Atmospheric Science, Dalhousie University, Halifax, B3H 3J5, Canada and at Environment \\ Canada, Toronto, M3H 5T4, Canada \\ ** now at: Dept. of Biophysics, Graduate School of Science, Kyoto University, Sakyo Kyoto 606-8502, Japan
}

Correspondence to: S. Gagné (stephanie.gagne@dal.ca) and J. Leppä (johannes.leppa@fmi.fi)

Received: 10 February 2011 - Published in Atmos. Chem. Phys. Discuss.: 26 May 2011

Revised: 16 April 2012 - Accepted: 26 April 2012 - Published: 25 May 2012

\begin{abstract}
The charging state of aerosol populations was determined using an Ion-DMPS in Helsinki, Finland between December 2008 and February 2010. We extrapolated the charging state and calculated the ion-induced nucleation fraction to be around $1.3 \% \pm 0.4 \%$ at $2 \mathrm{~nm}$ and $1.3 \% \pm 0.5 \%$ at $1.5 \mathrm{~nm}$, on average. We present a new method to retrieve the average charging state for a new particle formation event, at a given size and polarity. We improve the uncertainty assessment and fitting technique used previously with an Ion-DMPS. We also use a new theoretical framework that allows for different concentrations of small ions for different polarities (polarity asymmetry). We extrapolate the ion-induced fraction using polarity symmetry and asymmetry. Finally, a method to calculate the growth rates from the behaviour of the charging state as a function of the particle diameter using polarity symmetry and asymmetry is presented and used on a selection of new particle formation events.
\end{abstract}

\section{Introduction}

The amount of particulate matter suspended in the air (aerosol) and its size distribution influence the Earth's climate and precipitation patterns (e.g. Twomey, 1991; Lohmann and Feichter, 2005; Myhre et al., 2009; Stevens and Feingold, 2009). These particles can be emitted into the atmosphere directly (primary aerosols) or nucleate and grow in the atmosphere (secondary aerosols). The latter is commonly called new particle formation (NPF) and growth. Model simulations show that nucleation is a dominant source of particle number concentration in the atmosphere, and a significant contributor of cloud condensation nuclei $(\mathrm{CCN}$, Spracklen et al., 2008; Merikanto et al., 2009; Pierce and Adams, 2009). New particle formation has been observed in a wide range of environments, and takes place frequently (e.g. Kulmala et al., 2004 and references therein). The frequency and the mechanisms involved in new particle formation depend on the type of environment where it takes place. For example, the phenomenon has been observed to take place on almost every sunny day in the African Savannah (Laakso et al., 2008) whereas it is observed on about every third day in the Finnish boreal forest (Dal Maso et al., 2005) but almost never in the Amazon rain forest (Ahlm et al., 2010).

The mechanisms responsible for new particle formation and their relative contribution also varies from one place to another (Manninen et al., 2010) and from one day to another (Laakso et al., 2007a; Gagné et al., 2008 and 2010) and even during nucleation (Laakso et al., 2007b). There are many proposed nucleation mechanisms and their contributions are not well known. However, two general categories of mechanisms can be distinguished: neutral mechanisms and ion-induced mechanisms. Neutral mechanisms include all mechanisms 
that do not involve an electric charge. Ion-induced mechanisms are those that involve one or more electric charges in the formation process. The presence of electric charges can enhance the condensation of vapours onto the seed particle, at least in certain atmospheric conditions (Lovejoy et al., 2004; Curtius et al., 2006). Due to the large number of instruments capable of measuring air ions (Hirsikko et al., 2011) and those capable of measuring total particle size distributions, we can distinguish charged and neutral aerosols and thus calculating the relative contribution of ion-induced nucleation to the new particle formation process is possible.

Several authors have studied the role of ion-induced nucleation in atmospheric new particle formation, both through modeling and measurements. Model simulations by $\mathrm{Yu}$ (2006, 2010) and Yu et al. (2008) and chamber experiment results (Svensmark et al., 2007) indicate that ion-mediated nucleation may be an important global source of aerosols. Svensmark et al. (2007) propose a correlation between the production of aerosol particles, and thus $\mathrm{CCN}$, by ioninduced nucleation and the 11-year solar cycle, which modulates the ionization rate of the atmosphere by galactic cosmic rays. However, other models and field measurements did not see any such correlation (Kazil et al., 2006; Kulmala et al., 2010 and references therein).

Many authors have found that negative and positive ions (charged particles) behaved in a different manner. At different rural sites (SMEAR II station in Hyytiälä, Hari and Kulmala, 2005 and Tahkuse station in Estonia Hõrrak et al., 1998) days with negative overcharging are more frequent than days with positive overcharging (Vana et al., 2006; Laakso et al., 2007a; Gagné et al., 2008). This tendency is characteristic for measurement sites where ion-induced nucleation is sometimes important under favourable conditions.

In urban environments, Iida et al. (2006) performed measurements near Boulder, Colorado and showed that the average contribution of ion-induced nucleation is about $0.5 \%$ for both polarities, indicating that ion-induced nucleation is a relatively unimportant contributor to new particle formation. Furthermore, Iida et al. (2008) characterized the new particle formation events observed at Tecamac, Mexico, and found that the nucleated particles are initially almost all electrically neutral. Manninen et al. (2010) presented the ioninduced fraction for 7 different European sites using Neutral clusters and Air Ion Spectrometers (NAIS). The contribution of ion-induced nucleation to total particle formation at $2 \mathrm{~nm}$ was typically in the range of 1 to $30 \%$. The ion-induced contribution appeared to be smallest in more polluted continental sites. On the other hand, measurements in a clean marine coastal environment also show the general dominance of neutral nucleation pathways in new particle formation events (Ehn et al., 2010b).

In this study, we use Ion-DMPS (Ion-Differential Mobility Particle Sizer) measurements (Laakso et al., 2007a) performed at the SMEAR III station (Järvi et al., 2009), in Helsinki, Finland to estimate the contribution of ion- induced nucleation and neutral nucleation to new particle formation. NAISs and the Ion-DMPS yield comparable results (Kerminen et al., 2010; Gagné et al., 2010) regarding this contribution. Investigations of the ion-induced fraction in urban areas are rare. To our knowledge, this is only the third such report, after those of Iida et al. (2006 and 2008).

We extrapolate the measured charging state to the size at which nucleation begins and retrieve the ion-induced fraction (see lexicon). The charging state is the ratio of the observed charged fraction to the equilibrium charged fraction. We compare two analysis methods to calculate the charging state for each diameter. We describe the behaviour of the charging state without using the assumption that the number of small ions is the same for both polarities, which was always assumed in previous studies. This set of equations is described in detail in Appendix A. We use the method developed by Kerminen et al. (2007), with and without assuming the polarity symmetry, to extrapolate the charging state at $d_{0}=1.5$ and $2 \mathrm{~nm}$ and subsequently calculate the contribution of ion-induced nucleation. We analysed our data set with both charging state analysis method in combination with both set of charging state equations (polarity symmetry or asymmetry) for a total of four methods. The growth rates in the size range $3-7 \mathrm{~nm}, 3-11 \mathrm{~nm}$ and $7-20 \mathrm{~nm}$ and the formation rates at $2 \mathrm{~nm}$ were calculated from DMPS measurements for a subset of NPF events and are presented in this work. Finally, we use the behaviour of the charging state as a function of diameter to retrieve the growth rates, with a modified method of Iida et al. (2008). The version of the method used in this study does not include the effect of coagulation processes on the charging state, but it is adapted to work with or without the polarity symmetry assumption according to the derivation in Appendix A.

\section{Instrumentation and methods}

\subsection{SMEAR III station}

The site is considered a mildly polluted urban area. The Helsinki metropolitan area consists of 4 cities (Helsinki, Espoo, Vantaa and Kauniainen) accounting for a population of about one million inhabitants. The SMEAR III station (Station for Measuring Ecosystem-Atmosphere Relations III, Järvi et al., 2009), situated in Helsinki, has been in operation since August 2004, after which more instruments have gradually been added. The station is situated in Kumpula, $5 \mathrm{~km}$ north-east of the Helsinki city center. Kumpula is situated close to a residential area, a small botanical garden and a park, as well as streets with a relatively high traffic intensity. According to Järvi et al. (2009), ultrafine particles are most influenced by the nearby traffic emissions. The Ion-DMPS was sampling from an inlet at the fourth floor of Kumpula's Physicum building, $40 \mathrm{~m}$ a.s.l.-about $20 \mathrm{~m}$ above the ground-and at about $150 \mathrm{~m}$ north of the SMEAR III 
station. All the other instruments used in this study were situated either in a ground-level cottage (SMEAR III) or on the roof of the Physicum building (5 floors in total).

\subsection{Ion-DMPS}

The Ion-DMPS (Laakso et al., 2007a, and also Mäkelä et al., 2003; Iida et al., 2006) is an instrument based on a Differential Mobility Particle Sizer (DMPS, Aalto et al., 2001) with the addition of a few modifications. A DMPS gives the size distribution of particles in time and selects the mobility equivalent diameter in a stepwise function. First, the particles are charged to a known distribution through a neutralizer, then the particles are size segregated by a Differential Mobility Analyzer (DMA, Winklmayr et al., 1991) and, finally, counted with a particle counter (CPC, TSI 3025, Stolzenburg and McMurry, 1991).

In the Ion-DMPS set-up, the neutralizer can be switched on or off, making it possible to measure the concentration of charged particles in ambient and in neutralized mode with the same diffusional losses. Since we are interested in the ratio of the concentrations, no inversion takes place. Another difference with the DMPS is that the voltage in the DMA can be negative or positive, so that particles of both polarities can be classified. By combining these two modifications, the Ion-DMPS measures the size distribution in 4 modes: (1) ambient negatively charged particles, (2) neutralized negatively charged particles, (3) ambient positively charged particles and (4) neutralized positively charged particles.

The Ion-DMPS was originally operating in a boreal forest environment at SMEAR II (Hari and Kulmala, 2005), Finland from April 2005 to November 2008 (results available in Laakso et al., 2007a; Gagné et al., 2008 and 2010). It was then moved to Helsinki to be used in the laboratory (Physicum) and was measuring outdoor air when it was not otherwise in use. The dataset analysed in this manuscript expands from 8 December 2008 until 24 February 2010. The Ion-DMPS was measuring outdoor air on roughly $60 \%$ of the days during that period.

Due to higher particle concentrations at the urban SMEAR III station (Helsinki) compared to the background SMEAR II station (Hyytiälä), the Ion-DMPS was counting particles between 1.0 and $11.5 \mathrm{~nm}$ on 11 channels. The measurements of sub- $3 \mathrm{~nm}$ particles are less reliable, because of the CPC's limitations and, on most days, no data points were available below this size. In practice, on most days, the data spans from 2.5 to $11.5 \mathrm{~nm}$. Due to these additional channels and adjustments in integration times, the 4-mode cycle lasted about 27 min.

All days on which the Ion-DMPS was measuring were classified into 3 categories: events, non-events, and undefined days, based on the classification described in Gagné et al. (2008). Event days were the days for which the IonDMPS detected appearance of new particles at small sizes, and their growth to the upper diameter range of the instru- ment. Non-event days were the days for which no such appearance or growth was seen. Days for which the data displayed either appearance of particles at small sizes but no growth or other unusual dynamical features were classified as undefined. Days on which only partial data was available, or on which the Ion-DMPS was not measuring, were not classified. Event days took place on $15 \%$ of the classified days, $15 \%$ were undefined and $70 \%$ were non-event days.

Thirty-nine event days were found and further classified into undercharged, overcharged and steady-state days, using the method described in Laakso et al. (2007a) and Gagné et al. $(2008,2010)$. An overcharged particle population is defined as a population that has a higher fraction of charged particles than the bipolar equilibrium charged fraction; oppositely, an undercharged particle population has a lower fraction of charged particles than the bipolar equilibrium charged fraction. When the fraction is very close to the bipolar equilibrium charged fraction, it is called a steady-state particle population. Due to the equilibrium charged fraction being very small, and implying little ion-induced nucleation, steady-state events were grouped with undercharged events, as was done and explained in Gagné et al. (2010). For each event day, each polarity was classified by comparing the ambient and neutralized distributions visually. We also used data from a DMPS (Aalto et al., 2001) placed at the SMEAR III station and measuring in the $3-1000 \mathrm{~nm}$ size range, to estimate the growth rates and formation rates of a subset of dynamically well-behaved NPF events.

\subsection{Analytical methods}

\subsubsection{Charging state retrieval: time averaging and slopes}

There are several methods to calculate an average charging state for a given event, size and polarity. In this paper, we present two different methods. The first method, described in more detail in Gagné et al. (2008), consists in calculating the charging state as a function of time, and averaging it over the time when new particle formation takes place (see Fig. 1). The second, new method was inspired from a method used to analyse Neutral cluster and Air Ion Spectrometer (NAIS) data and is described in Vana et al. (2006). The new method, adapted for Ion-DMPS data, is similar to the first method in that only one average value over the time span of the NPF event is obtained for each diameter. We first plot the concentration of ions in the ambient mode against the corresponding concentration of ions in the neutralized mode for the selected diameter and period. Then, a least-mean square linear fit is made through the points, forcing the fit through the origin. The slope becomes the average charging state for the given diameter (see Fig. 2). The charging state as a function of the diameter is required to calculate the ion-induced fraction i.e. the fraction of new particles generated via ion-induced nucleation. 
The uncertainties in the two methods described above are estimated in slightly different ways. The uncertainty of the diameter is common to both of them, and depends on flow fluctuations in the DMA as well as the DMA's transfer function and voltage input. The edges of the box correspond to the half-height of the theoretical transfer function that the classified particle has at a given diameter. The uncertainty of the charging state, however, is calculated in different manners depending on the method. In the time averaged method, the uncertainty of the charging state is the standard deviation of the charging state over time. In this case, taking the ratio of averaged concentrations would not allow for the evaluation of the variability of the charging state. In the slope method, the uncertainty is the sum of that in the concentration and that attributable to the scatter around the linear fit.

\subsubsection{Extrapolation of the charging state: polarity symmetry}

In this paper, we use two different theoretical frameworks: one that assumes that the number concentration of small ions below $1.8 \mathrm{~nm}$ is the same for negative and positive ions $\left(N_{\mathrm{C}}^{-}=N_{\mathrm{C}}^{+}=N_{\mathrm{C}}\right)$ and also that the value of the negative and positive charged fraction is the same $\left(f^{+}=f^{-}\right)$, which we call polarity symmetry; and another, described in Sect. 2.3.3, that assumes a different number concentration for negative and positive small ions $\left(N_{\mathrm{C}}^{-} \neq N_{\mathrm{C}}^{+}\right)$and charged fractions $\left(f^{+} \neq f^{-}\right)$, which we call polarity asymmetry.

In the case where we assume polarity symmetry, the charging state $S^{ \pm}$can be defined, for theoretical purposes, as the ratio of the ambient charged fraction $\left(f^{ \pm}=N^{ \pm} / N_{\text {tot }}\right)$ to the neutralized charged fraction $\left(f_{\mathrm{eq}}^{ \pm}=\beta^{ \pm} / \alpha\right)$. Kerminen et al. (2007) developed an equation to describe the behaviour of the charging state $S^{ \pm}$as a function of the diameter $d_{\mathrm{p}}$ :

$S^{ \pm}\left(d_{\mathrm{p}}\right)=1-\frac{1}{K d_{\mathrm{p}}}+\frac{\left(S_{0}^{ \pm}-1\right) K d_{0}+1}{K d_{\mathrm{p}}} e^{-K\left(d_{\mathrm{p}}-d_{0}\right)}$

where

$K=\frac{\alpha N_{\mathrm{C}}}{\mathrm{GR}}$

and $S_{0}^{ \pm}$and $d_{0}$ are the charging state and diameter of newly formed particles, respectively, $N_{\mathrm{C}}^{ \pm}$is the number concentration of small ions, GR is the particle growth rate and $\alpha$ $\left(\sim 1.6 \times 10^{-6} \mathrm{~cm}^{3} \mathrm{~s}^{-1}\right)$ is the ion-ion recombination coefficient. Kerminen et al. (2007) make a number of assumptions that are all verified to be reasonable in the Helsinki atmospheric conditions (at least as much as they were for Hyytiälä conditions), excluding the assumption that the concentration of small ions is the same for both polarities.

We therefore fitted Eq. (1) to the measured charging states, $S^{ \pm}=S_{\text {meas }}^{ \pm}$, with $S_{0}^{ \pm}$and $K$ as free parameters. $S_{\text {meas }}^{ \pm}$is the charging state measured with the Ion-DMPS. $S_{0}^{ \pm}$was limited to the maximum charging state possible ( $100 \%$ of 1.5 or
$2 \mathrm{~nm}$ particles charged) and -10 for a minimum. $K$ was limited between 0.1 and $5 \mathrm{~nm}^{-1} . S_{0}^{ \pm}$was allowed to go below zero, even though the value is non-physical, in order to allow more freedom in fitting the curve. The value of $K$ becomes unrealistic below $0.1 \mathrm{~nm}^{-1}$ and the fit is no longer valid for very large values of $K$, hence an upper limit of $5 \mathrm{~nm}^{-1}$ was set for the fittings. However, all values above $2 \mathrm{~nm}^{-1}$ were discarded in the quality check because at high values of $K$, the particle population does not bear memory of its previous charging state. The fitting method consisted of generating normally distributed points inside each measured point's uncertainty box (Kerminen et al., 2007, Figs. 9, 10) and fit Eq. (1) through these points. In this work, the randomly generated points are situated more tightly inside the uncertainty boxes than they previously were in previous work. Two thousand fits were made for each event day and polarity, the median $S_{0}^{ \pm}$value and its corresponding $K$ value were taken as the representative values, along with the median absolute deviation (MAD) as an error estimate. The MAD is a value reflecting how much the charging state varies from one fit to another due to measurement uncertainty (Gagné et al., 2008). An example of the fitting method is shown in Fig. 3.

In the work of Kerminen et al. (2007) and Gagné et al. (2008), the ion-induced nucleation fraction was estimated using the time averaged method. We have improved our uncertainty evaluation, which is described in Sect. 2.3.1. We have also constrained the randomly generated points better within the limits of the boxes. These modification reduced the magnitude of the MAD, but also the range within which the fits were made and, as a consequence, we could raise the quality standard's definitions described in Sect. 3.2. These changes in the evaluation of the uncertainty do not have much effect on the values or charging state published in the above mentioned studies and they can still be trusted.

\subsubsection{Extrapolation of the charging state: taking the polarity asymmetry into account}

The equations used in this section are developed and explained in detail in Appendix A. In this work, we apply this new theoretical framework to Ion-DMPS measurements in Helsinki. If we reject the polarity symmetry assumption and instead use the framework of polarity asymmetry, i.e. when $N_{\mathrm{C}}^{-} \neq N_{\mathrm{C}}^{+}$and $f^{-} \neq f^{+}$, the equilibrium charged fraction is described as

$f_{\mathrm{eq}}^{ \pm}=\frac{\beta^{ \pm} N_{\mathrm{C}}^{ \pm}}{\alpha N_{\mathrm{C}}^{\mp}}$

The steady state value, or equilibrium value, in the asymmetric framework takes into account the difference in the attachment coefficients of negatively and positively charged small ions to neutral particles and also the difference in the concentrations of negatively and positively charged small ions, whereas the steady state in the symmetric framework only 

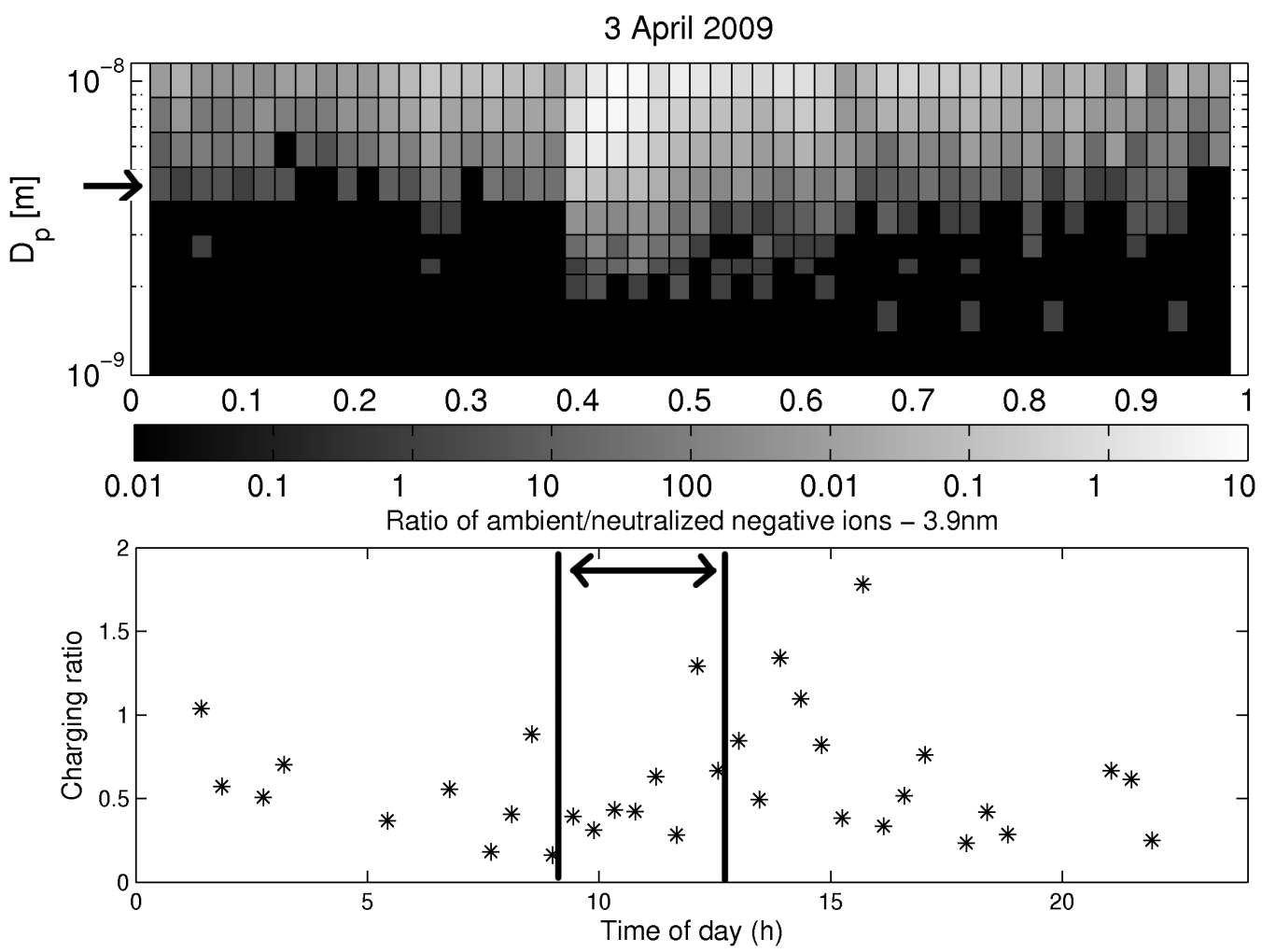

Fig. 1. Example of the determination of the average charging state at $3.9 \mathrm{~nm}$ (row shown by the arrow) for 3 April 2009 , negative polarity for the time averaged method. The charging state is plotted as a function of time. The data-analyst chooses the time span of new particle formation for the relevant diameter, indicated here by the vertical bars in the lower panel. The median charging state is kept as the average value.

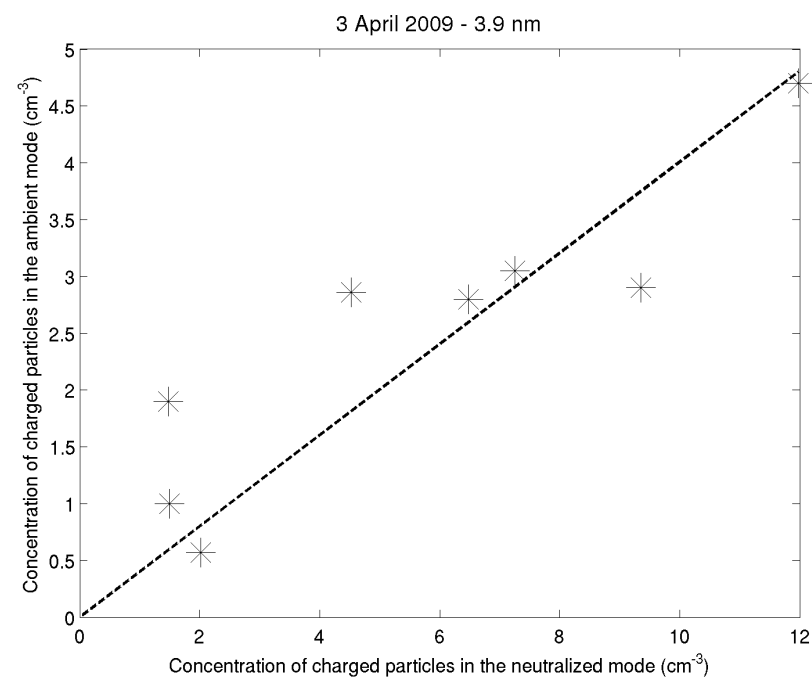

Fig. 2. Example of the determination of the average charging state at $3.9 \mathrm{~nm}$ for 3 April 2009, negative polarity for the slope method. The time span was the same as the one selected in Fig. 1. The concentration of charged particles in ambient mode is plotted as a function of the concentration in neutralized mode, so that the slope of the fit (forced to intercept the origin) is the average charging state at the given particle size. accounts for the difference in the attachment coefficients. If the concentrations of negative and positive small ions are the same, the equilibrium value given by Eq. (3) reduces into $f_{\mathrm{eq}}^{ \pm}=\beta^{ \pm} / \alpha$, the equilibrium charged fraction assumed by Kerminen et al. (2007).

In ambient conditions the particle population evolves towards the steady state with asymmetric small ion concentrations, but in the neutralizer of the Ion-DMPS, the particle population is assumed to reach the equilibrium with approximately the same concentrations of negatively and positively charged ions. With the Ion-DMPS, we measure the ambient concentration of charged particles and the concentration of charged particles after the particle population has passed the neutralizer, and thus we get the charging state with symmetric values of small ion concentration, $S_{\text {meas }}^{ \pm}$, as a ratio of these two values. We can take the asymmetric concentrations of small ions into account by scaling the values of $S_{\text {meas }}^{ \pm}$with the small ion concentrations according to

$$
S^{ \pm}=S_{\text {meas }}^{ \pm} \frac{N_{\mathrm{C}}^{\mp}}{N_{\mathrm{C}}^{ \pm}}
$$




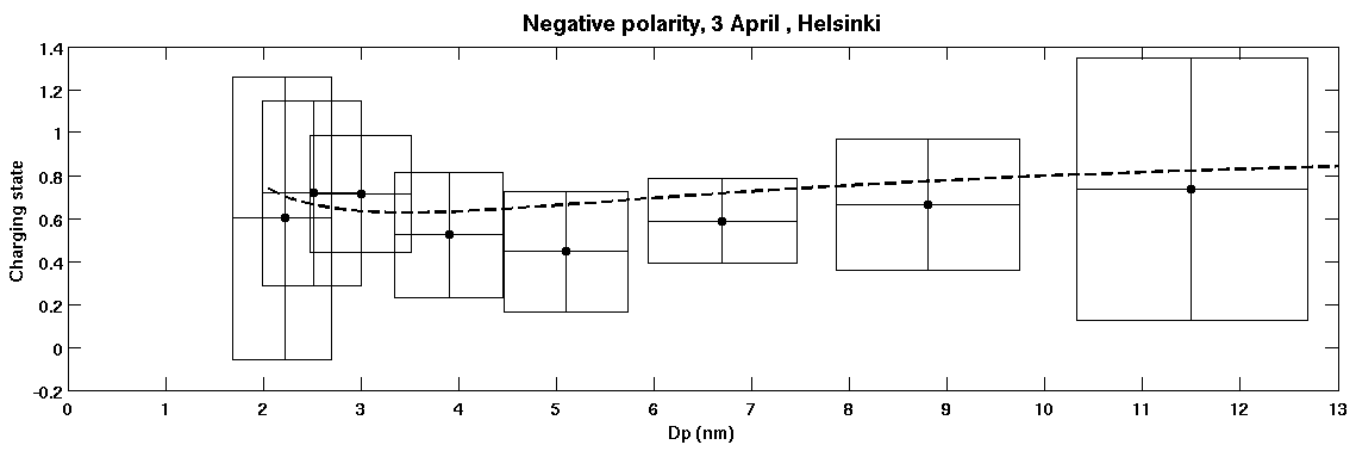

Fig. 3. Example of a fit to Eq. (5) for 3 April 2009, negative polarity. The dots or crosses in the boxes represent the measured points and the boxes around them, the uncertainty. The dashed line represents the fit (out of the 2000 generated fits) that yielded the median $S_{0}^{-}$value.

Now we can estimate the behaviour of the charging state as a function of diameter using the following equation (Appendix A):

$S^{ \pm}\left(d_{\mathrm{p}}\right)=1-\frac{1}{K^{ \pm} d_{\mathrm{p}}}+\frac{\left(S_{0}^{ \pm}-1\right) K^{ \pm} d_{0}+1}{K^{ \pm} d_{\mathrm{p}}} e^{-K^{ \pm}\left(d_{\mathrm{p}}-d_{0}\right)}$

where

$K^{ \pm}=\frac{\alpha N_{\mathrm{C}}^{\mp}}{\mathrm{GR}}$

Eq. (5) is different from Eq. (1) in two ways. Firstly, the asymmetric small ion concentrations are taken into account in the parameter $K^{ \pm}$according to Eq. (6). Secondly, the equilibrium charged fraction is extended to include the asymmetric concentrations of small ions according to Eq. (4). We can then use Eq. (5) to extrapolate the charging state to $d_{0}$ and obtain $S_{0}^{ \pm}$.

In this work, we used more than one year average of small ion concentration measured with a Balance Scanning Mobility Analyzer (BSMA) (Tammet, 2006) to scale $S_{\text {meas }}^{ \pm}$. The need for an average, instead of using the measurements on each particular day, stems from the fact that no ion spectrometers were measuring in Helsinki during the measurement period of the Ion-DMPS. The average values we used were $N_{\mathrm{C}}^{-}=436$ and $N_{\mathrm{C}}^{+}=563 \mathrm{~cm}^{-3}$, meaning that the concentration of positively charged small ions was slightly bigger than the concentration of negatively charged small ions.

\subsubsection{Four methods to retrieve the ion-induced nucleation fraction}

We presented two methods to retrieve the measured charging states for different diameters in Sect. 2.3.1 and two methods to extrapolate the charging state in Sects. 2.3.2 and 2.3.3 (using the polarity symmetry and asymmetry, respectively). We combined each of those methods to form four different methods. In order to ensure the clarity of the text, we renamed the four methods T0, TP, L0 and LP, according to the combination of methods used (Table 1). T represents the time average of the charging state, $\mathrm{L}$ represents charging state determined by slopes of linear fits through the concentrations in the ambient and neutralized modes, and 0 and $\mathrm{P}$ represent the symmetry assumption and the asymmetry inclusion for small ion concentrations, respectively. We consider LP to be the most advanced and reliable method of the four evaluated here.

To calculate the ion-induced nucleation fraction, we multiply the charging state $S_{0}^{ \pm}$of the event, obtained by fittings, by the equilibrium charged fraction $f_{\mathrm{eq}}^{ \pm}$. This gives the fraction of particles involved in nucleation that were charged at the diameter $d_{0}$, if we assume that the loss rates of neutral and charged particles at that diameter were the same. The equilibrium charged fraction used in this work is that given by Wiedensohler (1988). In the asymmetric case, the asymmetric charged fraction is used instead.

\subsubsection{Retrieving the growth rate from the charging state}

Iida et al. (2008) developed a method to calculate the growth rate of a NPF event from the evolution of the charged fraction as a function of the diameter $\left(\mathrm{GR}_{\mathrm{f}}\right)$. This method was developed because the growth rates in Mexico City were very high, and calculating them based on traditional methods (based on the particle size distribution, GR PSD $_{\text {, Dal Maso }}$ et al., 2005) was difficult. The instruments they used (an Inclined Grid Mobility Analyzer, IGMA, and a specially modified DMPS) are similar but not identical to the Ion-DMPS. The method was applied to NPF events taking place in Mexico City (with higher growth rates) and in Boulder, Colorado (with lower growth rates) and agreed well with GRPSD. In the case of Helsinki, the growth rates are generally small (below $5 \mathrm{~nm} \mathrm{~h}^{-1}$ ) and can be calculated with traditional methods when the NPF event is dynamically well behaved.

In the theoretical framework applied by Iida et al. (2008), the concentrations of oppositely charged small ions and oppositely charged nucleation mode particles were assumed to be similar. Omitting the effect of coagulation processes 
on the aerosol charging state and assuming that the attachment and recombination coefficients for both negatively and positively charged small ions are similar $\left(\beta^{-}=\beta^{+}=\beta\right.$ and $\alpha^{-}=\alpha^{+}=\alpha$ ), the particle growth rate in that framework can be expressed as:

$\mathrm{GR}_{\mathrm{f}}=\left(\frac{d f}{d d_{\mathrm{p}}}\right)^{-1} N_{\mathrm{C}}((1-2 f) \beta-\alpha f)$

By assuming that the charged fraction is small, $f \ll 1$, and that the steady state charged fraction is given by $f_{\text {eq }}=$ $\beta / \alpha$, Eq. (7) reduces to the similar equation given by Iida et al. (2008). When changing to our polarity asymmetric framework, we allow dissimilar values for concentrations of charged particles in the nucleation modes and for the concentrations, attachment coefficients and recombination coefficients of negatively and positively charged small ions. In this framework, the growth rate can be expressed as (see Appendix A for detail):

$\mathrm{GR}_{\mathrm{f}}=\left(\frac{d f^{-}}{d d_{\mathrm{p}}}\right)^{-1}\left(\left(1-f^{-}-f^{+}\right) \beta^{-} N_{\mathrm{C}}^{-}-\alpha^{+} f^{-} N_{\mathrm{C}}^{+}\right)$

$\mathrm{GR}_{\mathrm{f}}=\left(\frac{d f^{+}}{d d_{\mathrm{p}}}\right)^{-1}\left(\left(1-f^{+}-f^{-}\right) \beta^{+} N_{\mathrm{C}}^{+}-\alpha^{-} f^{+} N_{\mathrm{C}}^{-}\right)$

where $\alpha^{+}$and $\alpha^{-}$are the recombination coefficients of positively and negatively charged small ions to oppositely charged particles, respectively. The attachment and recombination coefficients used in our analysis were calculated according to the parametrized version (Hõrrak et al., 2008) of the theory presented by Hoppel and Frick (1986). In the derivation of Eqs. (8) and (9), all the particles are assumed to grow at the same rate, regardless of their size or charge.

We applied this new method to NPF events in Helsinki, and compared $\mathrm{GR}_{\mathrm{f}}$ to $\mathrm{GR}_{\mathrm{PSD}}$. The charged fraction as a function of diameter was obtained by numerically solving Eqs. (8) and 9 simultaneously with values of $\mathrm{GR}_{\mathrm{f}}$ and the initial charged fractions used as input. The initial size was chosen to be the smallest size for which the measured charged fractions were available for the particular case. $\mathrm{GR}_{\mathrm{f}}$ was then estimated minimizing the least square difference between the measured charged fractions and charged fractions calculated using Eqs. (8) and (9) with different values of $\mathrm{GR}_{\mathrm{f}}$ and initial charged fraction. This procedure was then repeated 2000 times with values of $f^{ \pm}$and corresponding $d_{\mathrm{p}}$ taken randomly from around the measured values, and $\mathrm{GR}_{\mathrm{f}}$ was obtained as an average of those repetitions. Growth rates were limited to between 0.5 and $30 \mathrm{~nm} \mathrm{~h}^{-1}$ to roughly correspond to the limits on the $K$ parameter.

It is possible that, for example due to missing data, it is desirable to estimate the growth rate from only either negative or positive charged fractions. This cannot be done using

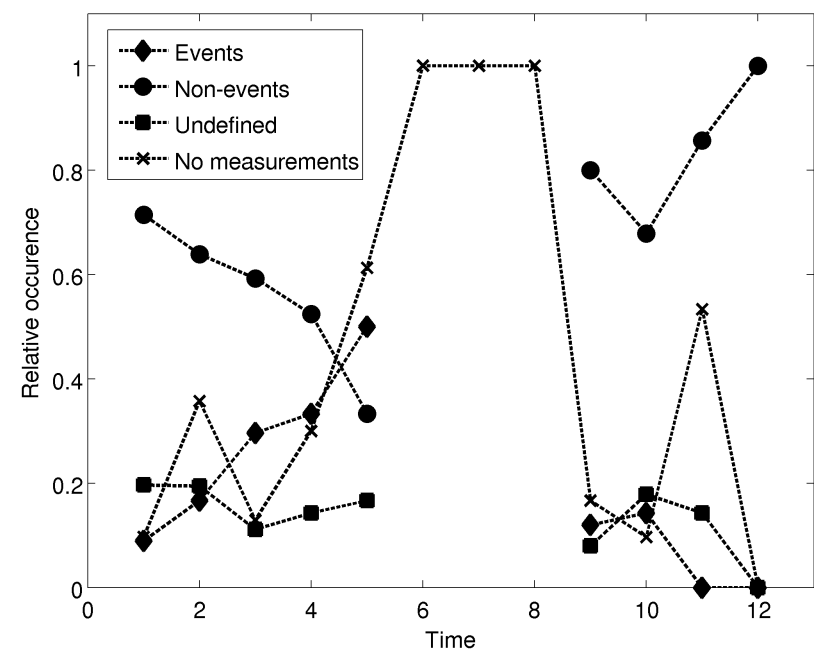

Fig. 4. Relative occurrence of event, non-event, undefined days (diamonds, circles and squares, respectively) as a function of the month of the year (percentage of measured days). The percentage of days without measurement is indicated by the no measurements line (crosses).

Table 1. Simplified names for each method based on the combination of the charging state averaging and the inclusion or not of the polarity asymmetry to Eqs. (1) and (5). T represents the median charging state during the time (time averaged method) of the NPF event and $\mathrm{L}$ represents the slope of a linear fit through the concentration of particles in the ambient mode as a function of the concentration of particles in the neutralized mode (slope method). The letters $\mathrm{T}$ and $\mathrm{L}$ are combined with either 0 , representing the polarity symmetry assumption for the concentration of small ions of both polarities, or P, representing the use of the polarity asymmetry.

\begin{tabular}{lcc}
\hline & $\begin{array}{c}\text { Polarity } \\
\text { symmetry }\end{array}$ & $\begin{array}{c}\text { Polarity } \\
\text { asymmetry }\end{array}$ \\
\hline $\begin{array}{l}\text { Time average of the charging } \\
\text { state }\end{array}$ & T0 & TP \\
Slopes of the Linear fits & L0 & LP \\
\hline
\end{tabular}

Eqs. (8) and (9), as both the negative and positive charged fractions are needed to solve the equations. However, if the charged fractions are assumed to be small $\left(f^{ \pm} \ll 1\right)$, then one can assume that $1-f^{+}-f^{-}=1$, in which case the Eqs. (8) and (9) can be used to estimate the $\mathrm{GR}_{\mathrm{f}}$ separately for both polarities.

\section{Results and discussion}

\subsection{General characteristics of the data set}

Each day of the measurement period was examined in search of new particle formation events. We classified the days into four categories: event, non-event, undefined and no 
measurements. The results are shown in Fig. 4. Unfortunately, there were no measurements made with the IonDMPS during the summer. However, based on DMPS measurements, only one NPF event took place during that time. Hussein et al. (2008) reported on several years of DMPS measurements in Helsinki and observed that the event frequency was higher in spring and autumn. Most of the events presented in this analysis are springtime events.

After finding $15 \%$ of the days to be event days (39 events), we then further classified the events into overcharged and undercharged classes. For the negative polarity, we found two overcharged days and 35 undercharged days (including steady-state days), and two days were not classified. For the positive polarity, we found nine overcharged days, 28 undercharged days and two days were not classifiable. The dominance of undercharged days in Helsinki indicates that the chemical or dynamical processes taking place in Helsinki may be different from those observed at the SMEAR II rural station, where most days are classified overcharged.

The formation and growth rates for each event were calculated using the method described by Kulmala et al. (2007) on DMPS data. The growth rates in the range 3-7 nm, 3-11 nm and $7-20 \mathrm{~nm}$ and new particle formation rates for 3 to $4 \mathrm{~nm}$ sized particles are summarized in Table 2. The growth rates in the literature are often divided into the 3-7 and 7-20 nm size ranges. In this paper, the growth rates in the 3-11 nm size range were also calculated because this is the range within which the Ion-DMPS and the DMPS overlap (see Sect. 3.3).

These 39 event days were selected based on Ion-DMPS data, however, the formation and growth rates were calculated based on DMPS data. It is thus very important to point out that most of the 39 days were not dynamically wellbehaved event days. The classification of NPF events was also done based on DMPS data using the method described by Dal Maso et al. (2005). Class I are days for which the formation and growth rates can be determined with a good confidence level. Class I events are divided into two subclasses: class Ia events that have high concentrations with little background concentration, suitable for modelling, all other class I events are in class Ib. Class II events are days for which it was not possible to determine the formation or growth rates at all, or the result may be questionable. Non-event days are the days where no NPF event took place. Finally, days were classified as undefined if it was not clear whether to classify them as event or non-event days. The DMPS classification of the 39 days presented in this work yielded only two type Ia events (21 March 2009 and 3 April 2009) and three type Ib events (19 March, 30 April and 14 October 2009). There were also seven type II events, three non-events and 22 undefined events, with two remaining days not yet being classified. We present growth rates and formation rates for class I events only.

By comparing the work of e.g. Gagné et al. (2008) and the dataset presented here, one notices some differences between the rural (Hyytiälä) and urban (Helsinki) sites. In par-
Table 2. Growth and formation rates based on DMPS data for class I events. The growth rates in the 3-7 $\mathrm{nm}$ size range (second column) is followed by the growth rates in the 3-11 and 7-20 $\mathrm{nm}$ size ranges. Finally, the total $3-4 \mathrm{~nm}$ particle formation rates are shown in the last column.

\begin{tabular}{lcccc}
\hline Date & $\mathrm{GR}_{3-7}$ & $\mathrm{GR}_{3-11}$ & $\mathrm{GR}_{7-20}$ & $J_{\text {tot3-4 }}$ \\
\hline 19 Mar 2009 & 3.8 & 2.8 & 2.3 & 0.5 \\
21 Mar 2009 & 3.2 & 2.4 & 1.7 & 0.7 \\
3 Apr 2009 & 7.5 & 2.2 & 2.7 & 2.7 \\
30 Apr 2009 & $\mathrm{NaN}$ & $\mathrm{NaN}$ & 4.1 & 0.4 \\
14 Oct 2009 & $\mathrm{NaN}$ & 2.1 & 1.4 & 0.4 \\
\hline
\end{tabular}

ticular, most of the event days at the rural site are overcharged, while those in the urban area are undercharged. A possible reason is that total nucleation rates are higher in urban environments, and if the charged nucleation rates are not scaled, then the fraction of ion-induced fraction decreases. This is consistent with Winkler et al. (2008) who show that charged condensation nuclei (first negatively charged, then positively charged) activate with smaller vapour saturation ratios than neutral ones. Hence in urban environments when the condensing vapour concentrations are high, there is enough vapour for neutral nucleation to occur, making the fraction of ion-induced nucleation smaller. This would be consistent with observations by Vana et al. (2006) and Gagné et al. (2010).

\subsection{Ion-induced fraction}

Each of the days that were classified as event days were analysed with each of the four methods. Tables B1, B2, B3 and B4 in the appendix show the results for methods T0, TP, L0 and LP, respectively. The results of all four methods are summarized in Table 3 as well as the LP method with the ion-induced fraction interpolated to $1.5 \mathrm{~nm}$ instead of $2 \mathrm{~nm}$. All methods yielded similar results: a low participation of ion-induced nucleation to new particle formation events measured in Helsinki.

Tables B1-B4 show the fitting results for 2000 fits per day per polarity, as well as their quality. The quality assessment of the fits as well as the rejection of data points was the same for all four methods. The quality of the fit is 1 if the median fit passes through every data-box and the trend follows the datapoints, 2 if the fit passes through most boxes or if it passes through all the boxes but the trend does not follow the datapoints, and 3 if the fit ignores the tendencies seen from the data points or if there is not enough data below $5 \mathrm{~nm}$. When the fit quality was 3 , the fitting parameters were all removed (indicated by "-"). Fits with a median charging state smaller than zero (non-physical result) are set to zero and their MAD removed. Fits with $K$ values larger than $2 \mathrm{~nm}^{-1}$ were also removed because large values of $K$ indicate that the information about the charging state is lost before we can measure it 
Table 3. This table summarizes the ion-induced fraction (IIN) at $2 \mathrm{~nm}$ and its median absolute deviation (MAD) statistics for each method: T0, TP, L0, LP and LP1.5, which is the LP method applied at $d_{0}=1.5 \mathrm{~nm}$ instead of $2 \mathrm{~nm}$. Detailed values for the fits at $2 \mathrm{~nm}$ can be seen from Tables B1 to B4 in Appendix B.

\begin{tabular}{lcccccccccc}
\hline & \multicolumn{2}{c}{ T0 } & \multicolumn{2}{c}{ TP } & \multicolumn{2}{c}{ L0 } & \multicolumn{2}{c}{ LP } & \multicolumn{2}{c}{ LP1.5 } \\
\cline { 2 - 10 } & IIN & MAD & IIN & MAD & IIN & MAD & IIN & MAD & IIN & MAD \\
\hline median & 1.1 & 1.4 & 1.4 & 1.1 & 1.2 & 0.5 & 1.3 & 0.4 & 1.3 & 0.5 \\
mean & 2.1 & 1.9 & 2.1 & 1.6 & 2.0 & 1.1 & 1.6 & 0.6 & 1.6 & 0.9 \\
std & 3.5 & 2.0 & 2.8 & 1.9 & 2.0 & 1.6 & 1.0 & 0.5 & 1.3 & 1.3 \\
min & 0.0 & 0.2 & 0.0 & 0.1 & 0.3 & 0.1 & 0.4 & 0.1 & 0.3 & 0.1 \\
max & 14.0 & 6.2 & 13.4 & 7.7 & 7.7 & 7.5 & 4.7 & 1.9 & 6.3 & 6.6 \\
rejected & $64 \%$ & $82 \%$ & $49 \%$ & $59 \%$ & $26 \%$ & $31 \%$ & $13 \%$ & $15 \%$ & $18 \%$ & $21 \%$ \\
\hline
\end{tabular}

(see Kerminen et al. (2007) and Gagné et al. (2008) for more explanations about the memory phenomena associated with the $K$ parameter).

Based on Table 3, we compare the methods T0, TP, L0 and LP at $2 \mathrm{~nm}$. All the values estimating uncertainty were smaller for the L methods ( $\mathrm{L} 0$ and $\mathrm{LP}$ ) than for the T methods (MADs $=0.5 \%$ and $0.4 \%$ rather than $1.4 \%$ and $1.1 \%$, for $\mathrm{L}$ and $\mathrm{T}$ methods, respectively). This suggests that the slope method was more stable than the time averaged method. Moreover, fewer fits were rejected when the charging state was retrieved using the slope method (L) than the time averaged method (T).

If we extrapolate the charging state to $1.5 \mathrm{~nm}$ instead of $2 \mathrm{~nm}$ (LP1.5, last two columns of Table 3), the ion-induced fraction is the same, and more fits are rejected than for LP at $2 \mathrm{~nm}$. The increase in the rejection rate is due to the fits varying more at small size. Since we extrapolate further to smaller diameters and the fit is not constrained by measurement points at this size, it is more likely to yield unphysical results and be rejected. However, the average MAD for nonrejected fits remained similar to the extrapolation down to $2 \mathrm{~nm}$.

The addition of the polarity asymmetry ( $\mathrm{P}$ methods) did not have a big effect on the ion-induced fractions, nor on their MAD. However, the rejection rates were lower for $\mathrm{P}$ methods. The polarity asymmetry becomes more important when using the charging state to retrieve growth rates, as will be discussed in Sect. 3.3. The P methods gave higher median values than their 0 counterparts. The same method applied to a sample of overcharged events from Hyytiälä showed no such tendency. The difference in the IIN fraction between the 0 methods and their P equivalent are well within the MAD, therefore we can conclude that, in the particular conditions found in Helsinki, the taking into account of the polarity asymmetry does not have an important effect on the IIN fraction estimations.

The T0 method was used by Gagné et al. (2008) in Hyytiälä. They observed a median contribution of ion-induced nucleation at $2 \mathrm{~nm}$ of $6.4 \%(\mathrm{MAD}=2.0 \%)$. The median contribution in Helsinki, using the same method, was $1.1 \%(\mathrm{MAD}=1.4 \%$, mean $=2.1 \%$ and standard deviation $=3.5 \%$ ). With the most up to date method (LP), the median ion-induced nucleation fraction was $1.3 \%(\mathrm{MAD}=0.4 \%$, mean $=1.6 \%$ and standard deviation $=1.0 \%$ ). The LP method extrapolating to $1.5 \mathrm{~nm}$ was also applied to the Helsinki dataset: the median ion-induced nucleation fraction was $1.3 \%(\mathrm{MAD}=0.5 \%$, mean $=1.6 \%$ and standard deviation $=1.3 \%$ ).

Figure 5 shows the extrapolated ion-induced nucleation fraction at $2 \mathrm{~nm}$, according to the LP method, as a function of the day of year. No clear seasonal tendency was observed in the variation of the ion-induced fraction. The majority of event days saw a contribution of ion-induced nucleation below 2,\%, with a maximum of $4.7 \%$. All high quality events but four had contributions below $2 \%$ and all were below $3 \%$.

\subsection{Growth rates}

We calculated the growth rates for class I event days using a method based on the particle size distribution (GRPSD, Kulmala et al., 2007) as well as the method based on the charging state $\left(\mathrm{GR}_{\mathrm{f}}\right)$ described in Sect. 2.3.5. The GR $\mathrm{PSD}$ based on DMPS measurements are presented in Table 2.

The growth rates were generally small (below $3 \mathrm{~nm} \mathrm{~h}^{-1}$ ). Iida et al. (2008) and Kerminen et al. (2007) both showed, with slightly different methods, that when the growth rate is small, the charged particles have enough time to recombine and thus lose their initial charge information before they can reach measurable sizes. In the work of Iida et al. (2008), the smallest GR PSD $_{\text {was }} 3.9 \mathrm{~nm} \mathrm{~h}^{-1}$, while in this work it varied between 2.1 and $2.8 \mathrm{~nm} \mathrm{~h}^{-1}$. The uncertainty in the values of $\mathrm{GR}_{\mathrm{PSD}}$ is estimated to be a factor two in both directions (Manninen et al., 2009a). In Fig. 6, we present Class I event

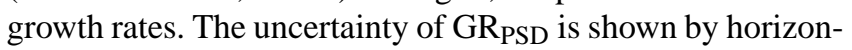
tal bars and those of $\mathrm{GR}_{\mathrm{f}}$ by vertical bars.

For both the asymmetric and the symmetric method, and for all variants of polarity (negative, positive or combined), the $\mathrm{GR}_{\mathrm{f}}$ are overestimated compared to GR $\mathrm{PSD}$. In the symmetric case, the growth rates are closer to GRPSD for the positive polarity and further away for negative polarity. One 
should remember that the number of positive small ions was larger than that of negative small ions. When the asymmetry of small ion concentration is introduced, the growth rates are more alike. The growth rates become closer to the expected value for negative particles whereas the growth rates for positive particles move further away from $\mathrm{GR}_{\mathrm{PSD}}$. When combining both polarities, the asymmetric case is closer to the expected values than the symmetric case. Moreover, the symmetric and asymmetric cases are closer to each other than when using only one polarity at the time. The values for negative symmetric growth rates would be above $30 \mathrm{~nm} \mathrm{~h}^{-1}$ if they were not limited to this value.

The growth rates determined using Eqs. (7)-(9) seem to be consistently higher than those determined from particle size distributions. This difference could be explained by concentrations of small ions that are significantly smaller on those particular days than the yearly-average values of small ion concentration used in the analysis. Whether this is the case cannot be verified because of the lack of measurements, but it seems unlikely that their concentrations would have been significantly smaller on each of the four days. Other explanations are that either the processes omitted in derivation of Eqs. (7)-(9), like coagulation, could have had a significant effect on the dynamics of the charged fractions on those days, or that the failure of the method was caused by instrumental errors. Both of these explanations are strengthened by the small growth rates observed during those four days, since the charging state approaches unity at very small sizes when the growth rate is small (Kerminen et al., 2007). In other words, we lose the signal of the growth rate to the noise caused by instrumental errors and processes omitted from the analysis.

\section{Conclusions}

In this work, we presented an analysis of 39 new particle formation events based on the Ion-DMPS classification scheme. We used a new method to calculate the charging state at each diameter that had never before been used on Ion-DMPS data. We also applied, for the first time, the theoretical background to calculate the charging state at $d_{0}$ without assuming that the concentration of negative and positive small ions is the same. To our knowledge, it is the first time that the polarity asymmetry was taken into account in estimating the charging state and the ion-induced fraction from measurements. We made an analysis of four methods using a combination of the following: (a) using either a time average of the charging state, or the slope of the least mean square fit of the concentrations in ambient and neutralized modes; and (b) using the polarity symmetry or the polarity asymmetry. We found that the slope method is superior to the time averaged method, reducing the MAD (median absolute deviation) by almost a factor of two.

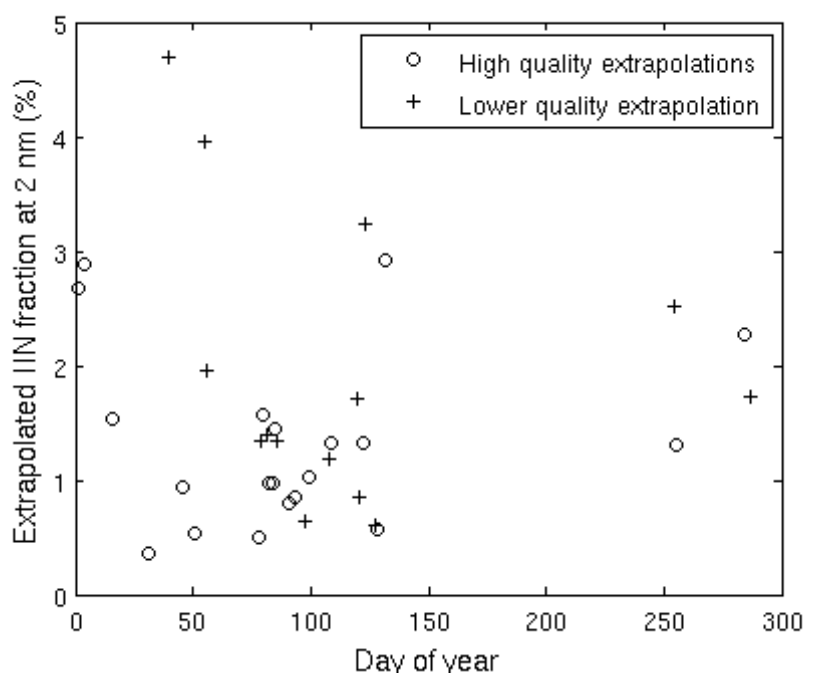

Fig. 5. Extrapolated ion-induced contribution at $2 \mathrm{~nm}$ as a function of the day of the year. The ion-induced contribution is calculated from the sum of the extrapolated negative and positive ion-induced fraction at $2 \mathrm{~nm}$. High quality extrapolations are those from days on which both the negative and positive fit quality value were 1 . All other ion-induced fractions are in the lower quality extrapolation category.

We also observed that the inclusion of the polarity asymmetry does not make much difference when it comes to determining the ion-induced fraction, at least in the conditions presented here, but reduced the rejection rate of median fits.

We used a method to estimate growth rates from the evolution of the charged fraction $\left(\mathrm{GR}_{\mathrm{f}}\right)$ that we compared with the traditional particle size distribution-based method GRPSD. The $\mathrm{GR}_{\mathrm{f}}$ method is a method inspired and modified from that described and used by Iida et al. (2008). The modified method can also be used assuming the polarity symmetry or asymmetry. We found that taking into account the polarity asymmetry made the growth rates of negative and positive polarity closer to each other. However, the $\mathrm{GR}_{\mathrm{f}}$ values seemed systematically overestimated, probably due to difficulties in estimating such small growth rates with our method, or instrumental errors.

Finally, we found that the ion-induced fraction in Helsinki was about $1.3 \%$ on average. This is consistent with the ion-induced fractions observed in other urban environments, where the fraction of ion-induced nucleation tends to be smaller than in remote areas. 


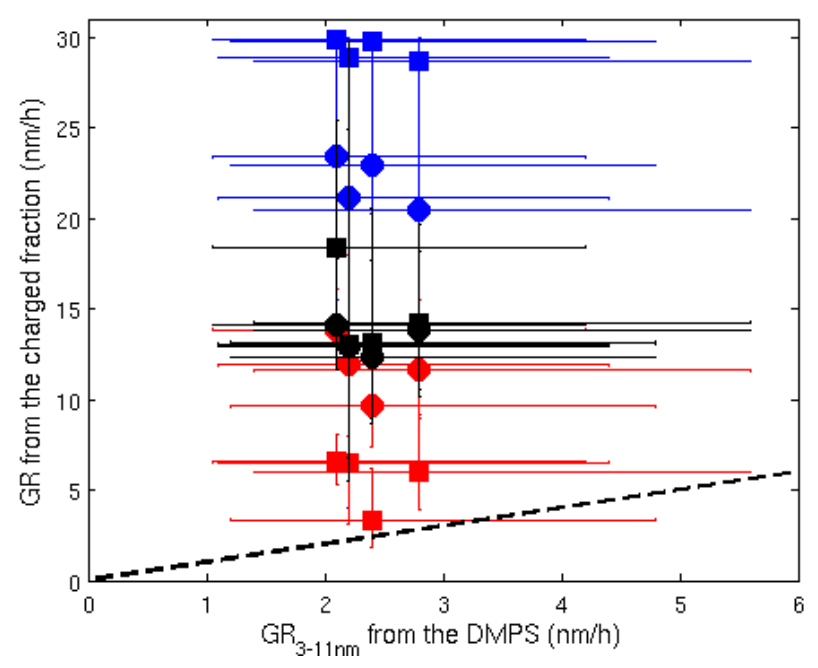

Fig. 6. Growth rate $\left(\mathrm{GR}_{\mathrm{f}}\right)$ calculated from the charging states as a function of the growth rate $\left(\mathrm{GR}_{\mathrm{PSD}}\right)$ between 3 and $11 \mathrm{~nm}$ for the four listed days that also belong to the DMPS class I. The circles represent the growth rates of the asymmetric cases and the squares represent the symmetric cases. The error bars for GR PSD is a factor of two, and the error bars for $\mathrm{GR}_{\mathrm{f}}$ are the 25 th and 75 th percentile of growth rates fitted through randomly generated points in the uncertainty boxes of the charged fraction as a function of the diameter. Blue are for growth rates based on negatively charged particles, red for those based on positively charged particles and black for the combination of both polarities. For the asymmetric case, we used: $N_{\mathrm{C}}^{-}=436 \mathrm{~cm}^{-3}$ and $N_{\mathrm{C}}^{+}=563 \mathrm{~cm}^{-3}$; for the symmetric case, we used: $N_{\mathrm{C}}=500 \mathrm{~cm}^{-3}$.

\section{Appendix A}

Derivation of equations governing the behaviour of aerosol charging state and charged fraction under asymmetric concentrations of small ions

Kerminen et al. (2007) derived an equation, which describes the behaviour of the aerosol charging state as a function of diameter. In the framework deployed by Kerminen et al. (2007), the fractions of charged particles in the nucleation mode as well as the concentrations of small ions were assumed to be equal for both polarities. Here, we reproduce this derivation in an asymmetric framework, i.e. without assuming that the negative and positive charged fractions or concentrations of negative and positive small ions are the same. However, the following assumptions made by Kerminen et al. (2007) hold also here: (1) The ion-ion recombination coefficient, $\alpha$, between two oppositely charged particles/ions is constant, with a value $\alpha=\sim 1.6 \times 10^{-6} \mathrm{~cm}^{3} \mathrm{~s}^{-1}$ used in this study; (2) The attachment coefficient, $\beta^{ \pm}$, between a small ion and a neutral particle with diameter $d_{\mathrm{p}}$ scales as $\beta^{ \pm}\left(d_{\mathrm{p}}\right)=\beta^{ \pm}\left(d_{0}\right)\left(d_{\mathrm{p}} / d_{0}\right)$; (3) All particles in the growing nucleation mode are neutral or singly charged; (4) The concentration of charged particles in the growing mode,
$N^{ \pm}$, is substantially smaller than the concentrations of small ions, $N_{\mathrm{C}}^{ \pm}$, i.e. $N^{ \pm} \ll N_{\mathrm{C}}^{ \pm}$; (5) The fractions of growing particles carrying a charge are substantially below unity, $f^{ \pm} \ll 1$; (6) Intermodal coagulation between nucleation mode particles and larger pre-existing particles does not significantly perturb the distribution of the charged fraction; (7) Selfcoagulation of nucleation mode particles is negligible, except for particles with opposite charges; (8) The particle diameter growth rate is the same for all particles regardless of their charge or diameter.

We define our system to consist of two particle modes: a nucleation mode with a mean diameter of $d_{\mathrm{p}}$ and a mode of larger pre-existing particles. A narrow nucleation mode may be approximated by a monodisperse mode, in which case the balance equations may be written as

$$
\begin{aligned}
\frac{d N^{0}}{d t}= & \alpha N_{\mathrm{C}}^{-} N^{+}+\alpha N_{\mathrm{C}}^{+} N^{-}-\beta^{-} N_{\mathrm{C}}^{-} N^{0} \\
& -\beta^{+} N_{\mathrm{C}}^{+} N^{0}-0.5 k_{0,0}\left(N^{0}\right)^{2}-k_{0,-} N^{0} N^{-} \\
& -k_{0,+} N^{0} N^{+}+\alpha N^{-} N^{+}-\mathrm{CoagS}_{0} N^{0} \\
\frac{d N^{-}}{d t}=- & \alpha N_{\mathrm{C}}^{+} N^{-}+\beta^{-} N_{\mathrm{C}}^{-} N^{0} \\
& -0.5 k_{-,-}\left(N^{-}\right)^{2}-\alpha N^{-} N^{+}-\mathrm{CoagS}_{-} N^{-}
\end{aligned}
$$

$$
\begin{aligned}
\frac{d N^{+}}{d t}= & -\alpha N_{\mathrm{C}}^{-} N^{-}+\beta^{+} N_{\mathrm{C}}^{+} N^{0} \\
& -0.5 k_{+,+}\left(N^{+}\right)^{2}-\alpha N^{-} N^{+}-\mathrm{CoagS}_{+} N^{+}
\end{aligned}
$$

where $N_{0}, N_{-}$and $N_{+}$are the concentrations of neutral, negatively charged and positively charged particles, respectively, and $N_{\mathrm{C}}^{-}$and $N_{\mathrm{C}}^{+}$are the concentrations of negative and positive small ions, respectively. Here $k_{0,0}, k_{0, \pm}$ and $k_{ \pm, \pm}$are the coagulation coefficients between two neutral particles, between a neutral and a charged particle and between two similarly-charged particles, respectively. The $\mathrm{CoagS}_{q}$ terms denote the scavenging rate of the nucleation mode particles with the charge $q$ (neutral, negatively or positively charged) due to coagulation with larger pre-existing particles.

By charge equilibrium we mean a state in which the neutralization of charged particles and charging of neutral particles at a given size are in balance and, as a consequence, the fraction of charged particles at that diameter does not change with time. The fractions of charged particles in the charge equilibrium, $f_{\text {eq }}^{ \pm}$, can be derived from the balance Eqs. (A1a)-(A1c), by setting the left hand side of the Eqs. (A1a)-(A1c) to zero and solving the ratios $N^{ \pm} / N_{\text {tot }}$. By assuming that the ion-aerosol attachment dominates 
over both self-coagulation and coagulation scavenging, the charged fractions in equilibrium can be written as

$f_{\mathrm{eq}}^{ \pm}=\frac{\beta^{ \pm} N_{\mathrm{C}}^{ \pm}}{\alpha N_{\mathrm{C}}^{\mp}+\beta^{ \pm} N_{\mathrm{C}}^{ \pm}+\beta^{\mp} \frac{\left(N_{\mathrm{C}}^{\mp}\right)^{2}}{N_{\mathrm{C}}^{ \pm}}}$.

By assuming further that $\alpha \gg \beta^{ \pm}$, Eq. (A2) simplifies to

$f_{\text {eq }}^{ \pm}=\frac{\beta^{ \pm} N_{\mathrm{C}}^{ \pm}}{\alpha N_{\mathrm{C}}^{\mp}}$

which gives the equilibrium charged fraction assumed by Kerminen et al. (2007), $f_{\text {eq }}^{ \pm}=\beta^{ \pm} / \alpha$, when the negative and positive small ion concentrations are similar.

If we neglect the self-coagulation terms from Eqs. (A1a)(A1c) according to assumption number 7 , the balance equations simplify to

$$
\begin{aligned}
\frac{d N^{0}}{d t} & =\alpha N_{\mathrm{C}}^{-} N^{+}+\alpha N_{\mathrm{C}}^{+} N^{-}-\beta^{-} N_{\mathrm{C}}^{-} N^{0} \\
& -\beta^{+} N_{\mathrm{C}}^{+} N^{0}+\alpha N^{-} N^{+}-\mathrm{CoagS}_{0} N^{0}
\end{aligned}
$$

$$
\begin{array}{r}
\frac{d N^{-}}{d t}=-\alpha N_{\mathrm{C}}^{+} N^{-}+\beta^{-} N_{\mathrm{C}}^{-} \\
N^{0}-\alpha N^{-} N^{+} \\
-\mathrm{CoagS}_{-} N^{-}
\end{array}
$$

$$
\begin{array}{r}
\frac{d N^{+}}{d t}=-\alpha N_{\mathrm{C}}^{-} N^{+}+\beta^{+} N_{\mathrm{C}}^{+} \\
N^{0}-\alpha N^{-} N^{+} \\
-\mathrm{CoagS}_{+} N^{+}
\end{array}
$$

By assuming that $f^{ \pm} \ll 1$ (assumption number 5), the time evolution of the charged fraction in the nucleation mode can be written as

$\frac{d f^{ \pm}}{d t}=\frac{1}{N^{0}} \frac{d N^{ \pm}}{d t}-\frac{f^{ \pm}}{N^{0}} \frac{d N^{0}}{d t}$.

If we combine Eqs. (A4)-(A5), the time evolution of the charged fractions can be written as

$$
\begin{aligned}
\frac{d f^{-}}{d t} & =N_{\mathrm{C}}^{-}\left(\left(\beta^{-}-\alpha f^{-} \frac{N^{+}}{N_{\mathrm{C}}^{-}}\right)\left(1+f^{-}\right)+\right. \\
& \left.f^{-} \frac{N_{\mathrm{C}}^{+}}{N_{\mathrm{C}}^{-}}\left(\beta^{+}-\alpha\left(1+f^{-}\right)\right)-\alpha f^{-} f^{+}\right) \\
& +f^{-}\left(\mathrm{CoagS}_{0}-\mathrm{CoagS}_{-}\right)
\end{aligned}
$$

$$
\begin{aligned}
\frac{d f^{+}}{d t} & =N_{\mathrm{C}}^{+}\left(\left(\beta^{+}-\alpha f^{+} \frac{N^{-}}{N_{\mathrm{C}}^{+}}\right)\left(1+f^{+}\right)+\right. \\
& \left.f^{+} \frac{N_{\mathrm{C}}^{-}}{N_{\mathrm{C}}^{+}}\left(\beta^{-}-\alpha\left(1+f^{+}\right)\right)-\alpha f^{-} f^{+}\right) \\
& +f^{+}\left(\mathrm{CoagS}_{0}-\mathrm{CoagS}_{+}\right)
\end{aligned}
$$

When the pre-existing aerosol loading is small, we can drop the last terms on the right hand side of Eqs. (A6a) and (A6b) (assumption number 6). Assuming also that both $f^{ \pm}$and $N^{ \pm} / N_{\mathrm{C}}^{ \pm}$are substantially below unity (assumptions 4 and 5), Eqs. (A6a) and (A6b) simplify to

$$
\begin{aligned}
& \frac{d f^{-}}{d t}=\beta^{-} N_{\mathrm{C}}^{-}-f^{-} \alpha N_{\mathrm{C}}^{+} \\
& \frac{d f^{+}}{d t}=\beta^{+} N_{\mathrm{C}}^{+}-f^{+} \alpha N_{\mathrm{C}}^{-} .
\end{aligned}
$$

The time evolution of the charging state of the growing nucleation mode can be written as

$$
\frac{d S^{-}}{d t}=\frac{d}{d t} \frac{f^{-}}{f_{\mathrm{eq}}^{-}}=\frac{1}{f_{\mathrm{eq}}^{-}}\left(\frac{d f^{-}}{d t}-S^{-} \frac{d f_{\mathrm{eq}}^{-}}{d t}\right)
$$

$$
\frac{d S^{+}}{d t}=\frac{d}{d t} \frac{f^{+}}{f_{\mathrm{eq}}^{+}}=\frac{1}{f_{\mathrm{eq}}^{+}}\left(\frac{d f^{+}}{d t}-S^{+} \frac{d f_{\mathrm{eq}}^{+}}{d t}\right) .
$$

By assuming that $f_{\text {eq }}^{ \pm}$is given according to Eq. (A3) and both $\alpha$ and $N_{\mathrm{C}}^{ \pm}$are constants, and by using Eqs. (A7a) and (A7b), the time evolution of the charging state can be written as

$$
\begin{aligned}
& \frac{d S^{-}}{d t}=\left(1-S^{-}\right) \alpha N_{\mathrm{C}}^{+}-\frac{S^{-}}{\beta^{-}} \frac{d \beta^{-}}{d t} \\
& \frac{d S^{+}}{d t}=\left(1-S^{+}\right) \alpha N_{\mathrm{C}}^{-}-\frac{S^{+}}{\beta^{+}} \frac{d \beta^{+}}{d t} .
\end{aligned}
$$


Following the approach by Kerminen and Kulmala (2002) as well as Kerminen et al. (2007), we next change the coordinate system by writing

$$
\frac{d}{d t}=\frac{d d_{\mathrm{p}}}{d t} \frac{d}{d d_{\mathrm{p}}}=\operatorname{GR}\left(d d_{\mathrm{p}}\right) \frac{d}{d d_{\mathrm{p}}} .
$$

Here GR is the growth rate of the particle diameter, which is assumed to be the same for both neutral and charged particles. Using Eqs. (A9)-(A10) and assumption 2, we get:

$$
\begin{aligned}
& \frac{d S^{-}\left(d_{\mathrm{p}}\right)}{d d_{\mathrm{p}}}=K^{-}-\left(K^{-}+\frac{1}{d_{\mathrm{p}}}\right) S^{-} \\
& \frac{d S^{+}\left(d_{\mathrm{p}}\right)}{d d_{\mathrm{p}}}=K^{+}-\left(K^{+}+\frac{1}{d_{\mathrm{p}}}\right) S^{+}
\end{aligned}
$$

where

$$
K^{ \pm}=\frac{\alpha N_{\mathrm{C}}^{\mp}}{\mathrm{GR}}
$$

Equations (A11-A12) describe the behaviour of the aerosol charging state as a function of particle diameter. Equations (A11a) and (A11b) can be analytically solved, if we assume that the particle growth rate is independent of particle size, in which case we get

$$
S^{ \pm}=1-\frac{1}{K^{ \pm} d_{\mathrm{p}}}+\frac{\left(S_{0}^{ \pm}-1\right) K^{ \pm} d_{0}+1}{K^{ \pm} d_{\mathrm{p}}} e^{-K^{ \pm}\left(d_{\mathrm{p}}-d_{0}\right)},
$$

where $S_{0}^{ \pm}$is the value of $S^{ \pm}$at size $d_{\mathrm{p}}=d_{0}$. Equation (A13) is similar to the one derived by Kerminen et al. (2007), with two notable differences. Firstly, the parameter $K^{ \pm}$ in Eq. (A13) depends on the concentration of oppositely charged small ions, $N_{\mathrm{C}}^{\mp}$, instead of the small ion concentration that is assumed to be the same for both polarities. Secondly, the definition of $f_{\mathrm{eq}}^{ \pm}$takes the small ion concentrations into account according to Eq. (A3).

Equation (A13), derived with various simplifying assumptions, describes the behaviour of the aerosol charging state as a function of diameter. Alternatively, we can describe the behaviour of the charged fraction as a function of diameter. We start from the balance Eqs. (A1a)-(A1c) and assume that the ion-aerosol attachment dominates over coagulation processes, in which case the balance equations can be written as

$$
\frac{d N^{0}}{d t}=\alpha^{-} N_{\mathrm{C}}^{-} N^{+}+\alpha^{+} N_{\mathrm{C}}^{+} N^{-}-\beta^{-} N_{\mathrm{C}}^{-} N^{0}-\beta^{+} N_{\mathrm{C}}^{+} N^{0}
$$

$\frac{d N^{-}}{d t}=-\alpha^{+} N_{\mathrm{C}}^{+} N^{-}+\beta^{-} N_{\mathrm{C}}^{-} N^{0}$

$$
\frac{d N^{+}}{d t}=-\alpha^{-} N_{\mathrm{C}}^{-} N^{+}+\beta^{+} N_{\mathrm{C}}^{+} N^{0} .
$$

Here, we do not need to make any assumptions on the diameter dependence of the attachment and recombination coefficients, $\beta^{ \pm}$and $\alpha^{ \pm}$, respectively, and we also use different coefficients in recombination of negative and positive small ions to oppositely charged particles, $\alpha^{-}$and $\alpha^{+}$, respectively. By solving the time evolution of the charged fractions, $f^{ \pm}$, from Eqs. (A14a)-(A14c) and by changing the coordinate system according to Eq. (A10), we get the following equations that can be used to estimate the value of the particle diameter growth rate:

$\mathrm{GR}_{\mathrm{f}}=\left(\frac{d f^{-}}{d d_{\mathrm{p}}}\right)^{-1}\left(\left(1-f^{-}-f^{+}\right) \beta^{-} N_{\mathrm{C}}^{-}-\alpha^{+} f^{-} N_{\mathrm{C}}^{+}\right)$

$\mathrm{GR}_{\mathrm{f}}=\left(\frac{d f^{+}}{d d_{\mathrm{p}}}\right)^{-1}\left(\left(1-f^{-}-f^{+}\right) \beta^{+} N_{\mathrm{C}}^{+}-\alpha^{-} f^{+} N_{\mathrm{C}}^{-}\right)$

If we assume symmetric small ion concentrations as well as charged fractions and assume $f^{ \pm} \ll 1$, Eqs. (A15a) and $(\mathrm{A} 15 \mathrm{~b})$ reduce to a similar equation derived by Iida et al. (2008). In their study, Iida et al. (2008) also took into account the effect of coagulation processes on the behaviour of the charged fraction as a function of diameter, a topic which is not covered in this study.

\section{Appendix B}

\section{Fit parameters for all analysed days and all methods}

The date in the first column followed by the median extrapolated charging state at $2 \mathrm{~nm}\left(\mathrm{~S}_{0}\right)$, its associated $K$ value, the MAD of the 2000 fits and the quality of the fit for each polarity. Finally, the last two columns show the fraction of ion-induced nucleation taking part in the NPF event, and its MAD. 
Table B1. Results for the median $S_{0}^{ \pm}$fit for each day for method T0: time average of the charging state, polarity symmetry.

\begin{tabular}{|c|c|c|c|c|c|c|c|c|c|c|}
\hline Date & $S_{0}^{-}$ & $K^{-}$ & $\begin{array}{c}\text { MAD } \\
S_{0}^{-}\end{array}$ & Q & $S_{0}^{+}$ & $K^{+}$ & $\begin{array}{c}\text { MAD } \\
S_{0}^{+}\end{array}$ & Q & $\begin{array}{l}\text { IIN } \\
(\%)\end{array}$ & $\begin{array}{c}\text { MAD } \\
\text { IIN }\end{array}$ \\
\hline 1 Jan 2009 & 0.99 & 0.10 & 0.32 & 1 & - & - & - & 3 & - & - \\
\hline 4 Jan 2009 & 1.17 & 0.10 & 0.55 & 1 & - & - & - & 1 & - & - \\
\hline 16 Jan 2009 & 0.30 & 0.11 & 0.09 & 1 & 1.60 & 0.41 & 2.25 & 2 & 1.45 & 1.76 \\
\hline 31 Jan 2009 & 0.25 & 0.10 & 0.10 & 1 & 1.65 & 0.14 & 0.78 & 2 & 1.45 & 0.67 \\
\hline 9 Feb 2009 & 1.01 & 0.10 & 0.14 & 1 & - & - & - & 3 & - & - \\
\hline 25 Feb 2009 & 1.01 & 0.10 & 0.31 & 1 & - & - & - & 3 & - & - \\
\hline 19 Mar 2009 & 0.47 & 0.17 & 0.46 & 1 & 0.00 & 1.00 & - & 2 & 0.39 & - \\
\hline 20 Mar 2009 & 1.06 & 0.15 & 0.26 & 1 & 0.00 & 0.94 & - & 1 & 0.88 & - \\
\hline 21 Mar 2009 & 1.04 & 0.12 & 0.28 & 1 & - & - & - & 2 & - & - \\
\hline 22 Mar 2009 & 0.52 & 0.19 & 0.24 & 1 & 0.00 & 1.17 & - & 1 & 0.43 & - \\
\hline 23 Mar 2009 & 0.00 & 0.10 & - & 1 & - & - & - & 3 & - & - \\
\hline 25 Mar 2009 & 0.68 & 0.13 & 0.12 & 1 & - & - & - & 3 & - & - \\
\hline 26 Mar 2009 & 0.48 & 0.15 & 0.65 & 1 & - & - & - & 2 & - & - \\
\hline 27 Mar 2009 & 0.73 & 0.10 & 0.17 & 2 & - & - & - & 3 & - & - \\
\hline 1 Apr 2009 & 0.01 & 0.12 & 0.19 & 1 & 0.00 & 1.96 & - & 2 & 0.01 & - \\
\hline 3 Apr 2009 & 0.50 & 0.12 & 0.26 & 1 & 0.00 & 1.10 & - & 1 & 0.42 & - \\
\hline 8 Apr 2009 & 0.76 & 0.10 & 0.35 & 1 & 1.59 & 0.10 & 0.56 & 1 & 1.82 & 0.71 \\
\hline 9 Apr 2009 & 0.11 & 0.15 & 0.58 & 1 & - & - & - & 3 & - & - \\
\hline 18 Apr 2009 & 0.78 & 0.45 & 0.07 & 1 & - & - & - & 1 & - & - \\
\hline 19 Apr 2009 & 0.76 & 0.24 & 0.07 & 1 & - & - & - & 1 & - & - \\
\hline 30 Apr 2009 & 1.35 & 0.10 & 0.24 & 1 & 1.91 & 0.33 & 1.58 & 2 & 2.55 & 1.38 \\
\hline 1 May 2009 & 0.50 & 0.15 & 1.77 & 1 & - & - & - & 3 & - & - \\
\hline 2 May 2009 & 1.18 & 0.18 & 0.34 & 2 & 0.00 & 1.70 & - & 1 & 0.98 & - \\
\hline 3 May 2009 & - & - & - & 3 & - & - & - & 3 & - & - \\
\hline 7 May 2009 & 0.68 & 0.10 & 0.24 & 1 & - & - & - & 3 & - & - \\
\hline 8 May 2009 & 0.87 & 0.10 & 0.17 & 1 & - & - & - & 3 & - & - \\
\hline 12 May 2009 & 0.78 & 0.17 & 0.25 & 1 & - & - & - & 2 & - & - \\
\hline 11 Sep 2009 & 1.55 & 0.15 & 0.34 & 1 & 0.00 & 1.09 & - & 1 & 1.29 & - \\
\hline 12 Sep 2009 & 1.73 & 0.10 & 0.17 & 1 & 1.96 & 0.25 & 3.00 & 1 & 2.91 & 2.39 \\
\hline 13 Sep 2009 & 1.39 & 0.10 & 0.15 & 1 & 17.17 & 0.73 & 8.08 & 1 & 14.03 & 6.18 \\
\hline 6 Oct 2009 & 0.62 & 0.14 & 0.20 & 2 & - & - & - & 3 & - & - \\
\hline 10 Oct 2009 & - & - & - & 3 & 0.64 & 1.66 & 0.10 & 2 & - & - \\
\hline 11 Oct 2009 & - & - & - & 3 & - & - & - & 3 & - & - \\
\hline 14 Oct 2009 & - & - & - & 3 & - & - & - & 3 & - & - \\
\hline 23 Jan 2010 & - & - & - & 3 & - & - & - & 3 & - & - \\
\hline 14 Feb 2010 & - & - & - & 3 & - & - & - & 3 & - & - \\
\hline 15 Feb 2010 & - & - & - & 3 & - & - & - & 3 & - & - \\
\hline 20 Feb 2010 & 0.37 & 0.10 & 0.09 & 1 & 0.47 & 0.28 & 0.21 & 1 & 0.66 & 0.23 \\
\hline 24 Feb 2010 & 0.57 & 0.10 & 0.50 & 1 & - & - & - & 3 & - & - \\
\hline median & 0.75 & 0.12 & 0.24 & & 0.47 & 0.94 & 1.18 & & 1.13 & 1.38 \\
\hline mean & 0.76 & 0.14 & 0.31 & & 1.80 & 0.86 & 2.07 & & 2.09 & 1.90 \\
\hline std & 0.43 & 0.07 & 0.31 & & 4.33 & 0.60 & 2.63 & & 3.54 & 2.02 \\
\hline $\min$ & 0.00 & 0.10 & 0.07 & & 0.00 & 0.10 & 0.10 & & 0.01 & 0.23 \\
\hline $\max$ & 1.73 & 0.45 & 1.77 & & 17.17 & 1.96 & 8.08 & & 14.03 & 6.18 \\
\hline
\end{tabular}


Table B2. Results for the median $S_{0}^{ \pm}$fit for each day for method TP: time average of the charging state, polarity asymmetry.

\begin{tabular}{|c|c|c|c|c|c|c|c|c|c|c|}
\hline Date & $S_{0}^{-}$ & $K^{-}$ & $\begin{array}{c}\text { MAD } \\
S_{0}^{-}\end{array}$ & Q & $S_{0}^{+}$ & $K^{+}$ & $\begin{array}{c}\text { MAD } \\
S_{0}^{+}\end{array}$ & Q & $\begin{array}{l}\text { IIN } \\
(\%)\end{array}$ & $\begin{array}{c}\text { MAD } \\
\text { IIN }\end{array}$ \\
\hline 1 Jan 2009 & 1.41 & 0.12 & 0.51 & 1 & 3.64 & 0.21 & 0.96 & 2 & 4.43 & 1.26 \\
\hline 4 Jan 2009 & 1.65 & 0.13 & 0.86 & 1 & 0.00 & 0.59 & - & 1 & 1.06 & - \\
\hline 16 Jan 2009 & 0.36 & 0.15 & 0.15 & 1 & 1.01 & 0.58 & 0.39 & 2 & 1.21 & 0.47 \\
\hline 31 Jan 2009 & 0.52 & 0.10 & 0.14 & 2 & 1.19 & 0.17 & 0.45 & 2 & 1.49 & 0.53 \\
\hline 9 Feb 2009 & 1.46 & 0.10 & 0.20 & 1 & - & - & - & 3 & - & - \\
\hline 25 Feb 2009 & 1.40 & 0.23 & 0.49 & 1 & - & - & - & 3 & - & - \\
\hline 19 Mar 2009 & 0.52 & 0.42 & 0.81 & 1 & 0.99 & 0.45 & 0.96 & 1 & 1.29 & 1.45 \\
\hline 20 Mar 2009 & 1.49 & 0.19 & 0.39 & 1 & 0.48 & 0.36 & 0.60 & 1 & 1.42 & 0.83 \\
\hline 21 Mar 2009 & 1.42 & 0.31 & 0.40 & 1 & 0.35 & 0.58 & 1.55 & 1 & 1.25 & 1.76 \\
\hline 22 Mar 2009 & 0.68 & 0.32 & 0.41 & 1 & 1.17 & 0.46 & 1.85 & 2 & 1.57 & 2.06 \\
\hline 23 Mar 2009 & 0.00 & 0.19 & - & 1 & - & - & - & 3 & - & - \\
\hline 25 Mar 2009 & 0.89 & 0.21 & 0.20 & 1 & - & - & - & 3 & - & - \\
\hline 26 Mar 2009 & 0.40 & 0.77 & 1.34 & 1 & 1.23 & 0.84 & 3.15 & 1 & 1.45 & 3.91 \\
\hline 27 Mar 2009 & 1.15 & 0.10 & 0.23 & 2 & - & - & - & 3 & - & - \\
\hline 1 Apr 2009 & 0.00 & 0.25 & - & 1 & 0.03 & 0.62 & 0.44 & 1 & 0.03 & - \\
\hline 3 Apr 2009 & 0.63 & 0.21 & 0.46 & 1 & 0.74 & 0.38 & 0.77 & 1 & 1.12 & 1.04 \\
\hline 8 Apr 2009 & 1.05 & 0.14 & 0.56 & 1 & 1.13 & 0.11 & 0.38 & 2 & 1.77 & 0.73 \\
\hline 9 Apr 2009 & 0.00 & 0.37 & 1.01 & 1 & - & - & - & 3 & - & - \\
\hline 18 Apr 2009 & 1.00 & 0.59 & 0.09 & 1 & - & - & - & 2 & - & - \\
\hline 19 Apr 2009 & 0.97 & 0.36 & 0.11 & 1 & 0.81 & 1.84 & 0.04 & 1 & 1.41 & 0.11 \\
\hline 30 Apr 2009 & 1.89 & 0.10 & 0.36 & 1 & 1.37 & 0.29 & 0.52 & 1 & 2.54 & 0.73 \\
\hline 1 May 2009 & 0.03 & 0.32 & 3.00 & 1 & - & - & - & 3 & - & - \\
\hline 2 May 2009 & 1.63 & 0.18 & 0.50 & 2 & 0.00 & 0.37 & - & 1 & 1.05 & - \\
\hline 3 May 2009 & - & - & - & 3 & - & - & - & 3 & - & - \\
\hline 7 May 2009 & 0.94 & 0.29 & 0.38 & 1 & - & - & - & 3 & - & - \\
\hline 8 May 2009 & 1.28 & 0.16 & 0.25 & 2 & - & - & - & 3 & - & - \\
\hline 12 May 2009 & 1.10 & 0.47 & 0.45 & 1 & 0.04 & 0.40 & 1.12 & 2 & 0.75 & 1.37 \\
\hline 11 Sep 2009 & 2.34 & 0.51 & 0.62 & 1 & 0.00 & 0.41 & - & 1 & 1.50 & - \\
\hline 12 Sep 2009 & 2.64 & 0.24 & 0.34 & 1 & 1.48 & 0.22 & 1.04 & 1 & 3.13 & 1.23 \\
\hline 13 Sep 2009 & 1.99 & 0.16 & 0.22 & 1 & 12.54 & 0.89 & 7.79 & 2 & 13.42 & 7.69 \\
\hline 6 Oct 2009 & 0.73 & 1.41 & 0.19 & 2 & - & - & - & 3 & - & - \\
\hline 10 Oct 2009 & - & - & - & 3 & 0.41 & 0.61 & 0.08 & 2 & - & - \\
\hline 11 Oct 2009 & - & - & - & 3 & - & - & - & 3 & - & - \\
\hline 14 Oct 2009 & - & - & - & 3 & - & - & - & 3 & - & - \\
\hline 23 Jan 2010 & - & - & - & 3 & - & - & - & 3 & - & - \\
\hline 14 Feb 2010 & - & - & - & 3 & - & - & - & 3 & - & - \\
\hline 15 Feb 2010 & - & - & - & 3 & - & - & - & 3 & - & - \\
\hline 20 Feb 2010 & 0.44 & 0.18 & 0.16 & 1 & 0.42 & 0.15 & 0.12 & 2 & 0.69 & 0.22 \\
\hline 24 Feb 2010 & 0.86 & 0.14 & 0.73 & 1 & - & - & - & 3 & - & - \\
\hline median & 0.99 & 0.21 & 0.40 & & 0.81 & 0.41 & 0.69 & & 1.42 & 1.13 \\
\hline mean & 1.03 & 0.29 & 0.52 & & 1.38 & 0.50 & 1.23 & & 2.13 & 1.59 \\
\hline std & 0.67 & 0.26 & 0.55 & & 2.68 & 0.37 & 1.80 & & 2.82 & 1.86 \\
\hline $\min$ & 0.00 & 0.10 & 0.09 & & 0.00 & 0.11 & 0.04 & & 0.03 & 0.11 \\
\hline $\max$ & 2.64 & 1.41 & 3.00 & & 12.54 & 1.84 & 7.79 & & 13.42 & 7.69 \\
\hline
\end{tabular}


Table B3. Results for the median $S_{0}^{ \pm}$fit for each day for method L0: slope of the linear fit passing through the concentration in the ambient mode as a function of the concentration in the neutralized mode, polarity symmetry.

\begin{tabular}{|c|c|c|c|c|c|c|c|c|c|c|}
\hline Date & $S_{0}^{-}$ & $K^{-}$ & $\begin{array}{c}\text { MAD } \\
S_{0}^{-}\end{array}$ & Q & $S_{0}^{+}$ & $K^{+}$ & $\begin{array}{c}\text { MAD } \\
S_{0}^{+}\end{array}$ & Q & $\begin{array}{l}\text { IIN } \\
(\%)\end{array}$ & $\begin{array}{c}\text { MAD } \\
\text { IIN }\end{array}$ \\
\hline 1 Jan 2009 & 0.69 & 0.13 & 0.23 & 1 & 5.89 & 1.59 & 2.64 & 2 & 4.99 & 2.17 \\
\hline 4 Jan 2009 & 0.24 & 0.18 & 0.23 & 1 & 8.88 & 1.69 & 9.77 & 1 & 6.86 & 7.52 \\
\hline 16 Jan 2009 & 0.49 & 0.11 & 0.14 & 1 & 1.81 & 0.84 & 0.70 & 1 & 1.76 & 0.64 \\
\hline 31 Jan 2009 & 0.05 & 0.11 & 0.09 & 1 & 0.33 & 0.28 & 0.26 & 1 & 0.29 & 0.27 \\
\hline 9 Feb 2009 & 0.45 & 0.11 & 0.18 & 2 & 4.81 & 0.56 & 1.07 & 1 & 3.98 & 0.95 \\
\hline 25 Feb 2009 & 0.76 & 0.14 & 0.15 & 2 & - & - & - & 3 & - & - \\
\hline 19 Mar 2009 & 0.61 & 0.19 & 0.20 & 1 & 0.00 & 0.91 & - & 1 & 0.51 & - \\
\hline 20 Mar 2009 & 0.94 & 0.10 & 0.13 & 2 & 0.78 & 0.47 & 0.24 & 2 & 1.37 & 0.29 \\
\hline 21 Mar 2009 & 1.19 & 0.12 & 0.14 & 1 & 0.00 & 1.49 & - & 2 & 0.99 & - \\
\hline $22 \operatorname{Mar} 2009$ & 0.95 & 0.16 & 0.13 & 1 & - & - & - & 2 & - & - \\
\hline 23 Mar 2009 & 0.26 & 0.10 & 0.08 & 1 & 1.01 & 0.50 & 0.16 & 1 & 0.97 & 0.19 \\
\hline 25 Mar 2009 & 0.33 & 0.16 & 0.10 & 1 & 0.91 & 0.65 & 0.51 & 1 & 0.96 & 0.47 \\
\hline 26 Mar 2009 & 0.77 & 0.13 & 0.14 & 1 & 1.09 & 0.43 & 0.72 & 1 & 1.46 & 0.66 \\
\hline 27 Mar 2009 & 0.73 & 0.10 & 0.19 & 2 & 1.00 & 0.10 & 0.23 & 1 & 1.36 & 0.33 \\
\hline 1 Apr 2009 & 0.39 & 0.24 & 0.07 & 1 & 0.53 & 0.95 & 0.34 & 1 & 0.72 & 0.31 \\
\hline 3 Apr 2009 & 0.58 & 0.11 & 0.11 & 1 & 0.45 & 1.84 & 0.39 & 2 & 0.82 & 0.38 \\
\hline 8 Apr 2009 & 0.32 & 0.26 & 0.09 & 2 & 0.56 & 0.20 & 0.40 & 1 & 0.69 & 0.37 \\
\hline 9 Apr 2009 & 0.87 & 0.17 & 0.15 & 1 & 0.36 & 0.31 & 0.23 & 1 & 0.99 & 0.30 \\
\hline 18 Apr 2009 & - & - & - & 2 & - & - & - & 2 & - & - \\
\hline 19 Apr 2009 & 0.71 & 0.14 & 0.08 & 1 & - & - & - & 1 & - & - \\
\hline 30 Apr 2009 & 1.39 & 0.10 & 0.13 & 1 & 0.32 & 1.59 & 0.60 & 2 & 1.39 & 0.56 \\
\hline 1 May 2009 & 0.59 & 0.16 & 0.14 & 1 & 0.42 & 0.45 & 0.31 & 1 & 0.80 & 0.35 \\
\hline 2 May 2009 & 0.78 & 0.10 & 0.16 & 1 & 0.70 & 0.58 & 0.49 & 1 & 1.17 & 0.50 \\
\hline 3 May 2009 & 0.93 & 1.65 & 0.80 & 2 & 6.43 & 0.83 & 4.72 & 2 & 5.59 & 4.20 \\
\hline 7 May 2009 & 0.47 & 0.10 & 0.20 & 1 & 0.20 & 0.40 & 0.29 & 2 & 0.54 & 0.38 \\
\hline 8 May 2009 & 0.26 & 0.10 & 0.07 & 1 & 0.49 & 0.31 & 0.33 & 2 & 0.58 & 0.31 \\
\hline 12 May 2009 & 0.93 & 0.12 & 0.18 & 1 & 9.26 & 1.02 & 4.80 & 2 & 7.72 & 3.75 \\
\hline 11 Sep 2009 & 1.51 & 0.19 & 0.36 & 1 & 1.96 & 0.85 & 1.80 & 1 & 2.72 & 1.65 \\
\hline 12 Sep 2009 & 0.68 & 0.18 & 0.31 & 1 & 0.98 & 0.84 & 0.58 & 1 & 1.30 & 0.69 \\
\hline 13 Sep 2009 & 1.28 & 0.10 & 0.26 & 1 & - & - & - & 3 & - & - \\
\hline 6 Oct 2009 & - & - & - & 3 & 0.47 & 0.50 & 0.11 & 2 & - & - \\
\hline 10 Oct 2009 & - & - & - & 3 & 0.68 & 1.98 & 0.12 & 2 & - & - \\
\hline 11 Oct 2009 & 1.14 & 0.10 & 0.45 & 1 & 2.15 & 0.42 & 1.10 & 2 & 2.56 & 1.20 \\
\hline 14 Oct 2009 & 1.47 & 0.10 & 0.46 & 1 & - & - & - & 2 & - & - \\
\hline 23 Jan 2010 & 0.00 & 0.10 & - & 2 & - & - & - & 3 & - & - \\
\hline 14 Feb 2010 & 0.00 & 0.11 & - & 1 & - & - & - & 3 & - & - \\
\hline 15 Feb 2010 & 0.36 & 0.10 & 0.24 & 1 & 0.85 & 0.14 & 0.58 & 1 & 0.94 & 0.63 \\
\hline 20 Feb 2010 & 0.22 & 0.11 & 0.05 & 1 & 0.46 & 0.19 & 0.13 & 1 & 0.53 & 0.14 \\
\hline 24 Feb 2010 & 3.16 & 0.10 & 1.02 & 2 & 0.64 & 0.10 & 0.41 & 1 & 3.10 & 1.15 \\
\hline median & 0.69 & 0.11 & 0.15 & & 0.70 & 0.56 & 0.41 & & 1.17 & 0.50 \\
\hline mean & 0.74 & 0.17 & 0.22 & & 1.76 & 0.74 & 1.17 & & 1.99 & 1.12 \\
\hline std & 0.58 & 0.26 & 0.20 & & 2.51 & 0.54 & 2.05 & & 1.98 & 1.63 \\
\hline $\min$ & 0.00 & 0.10 & 0.05 & & 0.00 & 0.10 & 0.11 & & 0.29 & 0.14 \\
\hline $\max$ & 3.16 & 1.65 & 1.02 & & 9.26 & 1.98 & 9.77 & & 7.72 & 7.52 \\
\hline
\end{tabular}


Table B4. Results for the median $S_{0}^{ \pm}$fit for each day for method LP: slope of the linear fit passing through the concentration in the ambient mode as a function of the concentration in the neutralized mode, polarity asymmetry.

\begin{tabular}{|c|c|c|c|c|c|c|c|c|c|c|}
\hline Date & $S_{0}^{-}$ & $K^{-}$ & $\begin{array}{c}\text { MAD } \\
S_{0}^{-}\end{array}$ & Q & $S_{0}^{+}$ & $K^{+}$ & $\begin{array}{c}\text { MAD } \\
S_{0}^{+}\end{array}$ & Q & $\begin{array}{l}\text { IIN } \\
(\%)\end{array}$ & $\begin{array}{c}\text { MAD } \\
\text { IIN }\end{array}$ \\
\hline 1 Jan 2009 & 0.92 & 0.22 & 0.34 & 1 & 2.16 & 0.84 & 0.68 & 1 & 2.68 & 0.88 \\
\hline 4 Jan 2009 & 0.22 & 0.30 & 0.36 & 1 & 2.83 & 1.68 & 1.58 & 1 & 2.88 & 1.76 \\
\hline 16 Jan 2009 & 0.67 & 0.14 & 0.19 & 1 & 1.15 & 0.27 & 0.30 & 1 & 1.54 & 0.41 \\
\hline 31 Jan 2009 & 0.10 & 0.10 & 0.14 & 1 & 0.31 & 0.19 & 0.17 & 1 & 0.36 & 0.25 \\
\hline 9 Feb 2009 & 0.60 & 0.14 & 0.24 & 1 & 4.45 & 0.81 & 1.55 & 2 & 4.70 & 1.66 \\
\hline 25 Feb 2009 & 0.98 & 0.29 & 0.22 & 2 & 1.37 & 1.41 & 1.21 & 1 & 1.96 & 1.31 \\
\hline 19 Mar 2009 & 0.78 & 0.61 & 0.24 & 1 & 0.00 & 0.51 & - & 1 & 0.50 & - \\
\hline 20 Mar 2009 & 1.19 & 0.27 & 0.15 & 2 & 0.60 & 0.36 & 0.13 & 1 & 1.35 & 0.22 \\
\hline 21 Mar 2009 & 1.60 & 0.32 & 0.21 & 1 & 0.56 & 0.50 & 0.61 & 1 & 1.57 & 0.73 \\
\hline 22 Mar 2009 & 1.27 & 0.27 & 0.18 & 1 & 0.59 & 0.77 & 0.43 & 2 & 1.39 & 0.53 \\
\hline 23 Mar 2009 & 0.35 & 0.19 & 0.11 & 1 & 0.77 & 0.10 & 0.11 & 1 & 0.97 & 0.18 \\
\hline 25 Mar 2009 & 0.41 & 0.32 & 0.13 & 1 & 0.73 & 0.22 & 0.25 & 1 & 0.97 & 0.33 \\
\hline 26 Mar 2009 & 1.02 & 0.31 & 0.19 & 1 & 0.81 & 0.25 & 0.35 & 1 & 1.44 & 0.46 \\
\hline 27 Mar 2009 & 0.98 & 0.10 & 0.25 & 2 & 0.73 & 0.10 & 0.18 & 1 & 1.34 & 0.34 \\
\hline 1 Apr 2009 & 0.50 & 0.26 & 0.10 & 1 & 0.48 & 0.40 & 0.18 & 1 & 0.79 & 0.24 \\
\hline 3 Apr 2009 & 0.75 & 0.48 & 0.15 & 1 & 0.38 & 0.42 & 0.23 & 1 & 0.85 & 0.32 \\
\hline 8 Apr 2009 & 0.37 & 0.29 & 0.13 & 2 & 0.42 & 0.11 & 0.29 & 1 & 0.64 & 0.36 \\
\hline 9 Apr 2009 & 1.14 & 0.18 & 0.20 & 1 & 0.30 & 0.23 & 0.15 & 1 & 1.02 & 0.27 \\
\hline 18 Apr 2009 & 1.00 & 0.69 & 0.07 & 2 & 0.57 & 0.84 & 0.02 & 1 & 1.19 & 0.06 \\
\hline 19 Apr 2009 & 0.90 & 0.47 & 0.10 & 1 & 0.77 & 1.28 & 0.03 & 1 & 1.32 & 0.09 \\
\hline 30 Apr 2009 & 1.87 & 0.10 & 0.18 & 1 & 0.52 & 0.68 & 0.28 & 2 & 1.71 & 0.39 \\
\hline 1 May 2009 & 0.75 & 0.12 & 0.20 & 1 & 0.38 & 0.37 & 0.18 & 2 & 0.85 & 0.30 \\
\hline 2 May 2009 & 1.01 & 0.26 & 0.22 & 1 & 0.69 & 0.22 & 0.20 & 1 & 1.32 & 0.34 \\
\hline 2 May 2009 & 1.01 & 0.26 & 0.22 & 1 & 0.69 & 0.22 & 0.20 & 1 & 1.32 & 0.34 \\
\hline 3 May 2009 & 2.05 & 0.39 & 0.83 & 2 & 1.98 & 0.26 & 0.48 & 2 & 3.24 & 1.00 \\
\hline 7 Мау 2009 & 0.68 & 0.10 & 0.26 & 1 & 0.18 & 0.26 & 0.18 & 2 & 0.61 & 0.34 \\
\hline 8 Маy 2009 & 0.36 & 0.14 & 0.10 & 1 & 0.35 & 0.13 & 0.24 & 1 & 0.57 & 0.30 \\
\hline 12 Мау 2009 & 1.24 & 0.35 & 0.25 & 1 & 2.19 & 0.35 & 0.33 & 1 & 2.92 & 0.48 \\
\hline 11 Sep 2009 & 2.19 & 0.38 & 0.86 & 1 & 1.15 & 0.42 & 0.50 & 2 & 2.52 & 1.04 \\
\hline 12 Sep 2009 & 0.88 & 0.38 & 0.53 & 1 & 0.77 & 0.27 & 0.33 & 1 & 1.31 & 0.66 \\
\hline 13 Sep 2009 & 1.81 & 0.10 & 0.47 & 2 & - & - & - & 3 & - & - \\
\hline 6 Oct 2009 & - & - & - & 3 & 0.36 & 0.18 & 0.09 & 2 & - & - \\
\hline 10 Oct 2009 & - & - & - & 3 & 0.49 & 1.39 & 0.13 & 2 & - & - \\
\hline 11 Oct 2009 & 1.67 & 0.22 & 0.66 & 1 & 1.24 & 0.22 & 0.42 & 1 & 2.27 & 0.83 \\
\hline 14 Oct 2009 & 2.13 & 0.31 & 1.15 & 2 & 0.37 & 0.59 & 0.18 & 1 & 1.73 & 0.91 \\
\hline 23 Jan 2010 & 0.12 & 0.10 & 0.29 & 1 & - & - & - & 3 & - & - \\
\hline 14 Feb 2010 & 0.04 & 0.10 & 0.31 & 1 & - & - & - & 3 & - & - \\
\hline 15 Feb 2010 & 0.50 & 0.10 & 0.33 & 1 & 0.63 & 0.10 & 0.36 & 1 & 0.93 & 0.56 \\
\hline 20 Feb 2010 & 0.28 & 0.14 & 0.07 & 1 & 0.36 & 0.16 & 0.09 & 1 & 0.53 & 0.13 \\
\hline 24 Feb 2010 & 5.50 & 0.24 & 2.40 & 2 & 0.43 & 0.10 & 0.32 & 2 & 3.95 & 1.85 \\
\hline median & 0.90 & 0.26 & 0.2 & & 0.6 & 0.31 & 0.2 & & 1.33 & 0.39 \\
\hline mean & 1.05 & 0.26 & 0.35 & & 0.89 & 0.47 & 0.36 & & 1.59 & 0.59 \\
\hline std & 0.95 & 0.15 & 0.42 & & 0.87 & 0.41 & 0.37 & & 1.02 & 0.48 \\
\hline $\min$ & 0.04 & 0.10 & 0.07 & & 0.00 & 0.10 & 0.02 & & 0.36 & 0.06 \\
\hline $\max$ & 5.50 & 0.69 & 2.40 & & 4.45 & 1.68 & 1.58 & & 4.70 & 1.85 \\
\hline
\end{tabular}




\section{Lexicon}

Charged fraction $(f)$. Fraction of particles that are electrically charged.

Charging state $(S)$. Ratio of the charged fraction and the equilibrium charged fraction. Also the ratio of the concentration of naturally charged particles to the concentration of charged particles after going through a neutralizer that forces the sample into bipolar equilibrium. $S_{0}=S\left(d_{0}\right)$ is the charging state at the diameter at which new particle formation is determined to occur, $d_{0} . S_{\text {meas }}$ is the charging state obtained directly from Ion-DMPS measurements.

Equilibrium charged fraction $\left(f_{\mathrm{eq}}\right)$. The fraction of particles that are charged in a steady-state, i.e. when the charging of neutral particles and neutralization of charged particles are at balance. Relative concentrations of negative and positive small ions affect the equilibrium charged fraction. An air sample is assumed to be in steady state with symmetric concentrations of small ions after passing through a neutralizer.

Ion-induced nucleation fraction. The fraction of nucleation mode particles of which the nucleation involved an electric charge at diameter $d_{0}$, expressed in percent.

Polarity asymmetry. When the concentration of small ions for positively and negatively charged particles is different.

Polarity symmetry. When the concentration of small ions for positively and negatively charged particles is about the same.

Slope method ( $L O$ or $L P$ ). Method by which the charging state is calculated for a given size. The plot of the ambient ion concentration as a function of the neutralized ion concentration during the NPF event is drawn. The slope of a linear fit forced through the origin is the average charging state.

Small ions (concentration: $N_{\mathrm{C}}$ ). Small ions are charged particles of mobility diameters between 0.4 and $1.8 \mathrm{~nm}$, below the apparent nucleation size. In this work, they are measured with a Balanced Scanning Mobility Analyzer (BSMA).

Time averaged method (TO or TP). Method by which the charging state is calculated for a given size. The charging state is calculated and averaged over the time of the NPF event.

Acknowledgements. This research was supported by the Academy of Finland Center of Excellence program (project number 1118615), and the European Commission 6th Framework program project EUCAARI, contract no. 036833-2 (EUCAARI). Bjarke Molgaard is acknowledged for providing the DMPS event classification. Petri Keronen and Pasi P. Aalto are acknowledged for maintaining the SMEAR III station and providing the DMPS data.

Edited by: E. Swietlicki

\section{References}

Aalto, P. P., Hämeri, K., Becker, E., Weber, R., Salm, J., Mäkelä, J. M., Hoell, C., O’Dowd, C. D., Karlsson, H., Hansson, H.-C., Väkevä, M., Koponen, I. K., Buzorius, G., and Kulmala, M.: Physical characterization of aerosol particles during nucleation events, Tellus, 53B, 344-358, 2001.

Ahlm, L., Nilsson, E. D., Krejci, R., Mårtensson, E. M., Vogt, M., and Artaxo, P.: A comparison of dry and wet season aerosol number fluxes over the Amazon rain forest, Atmos. Chem. Phys., 10, 3063-3079, doi:10.5194/acp-10-3063-2010, 2010.

Curtius, J., Lovejoy, E. R., and Froyd, K. D.: Atmospheric ioninduced aerosol nucleation, Space Sci. Rev., 125, 159-167, 2006.

Dal Maso, M., Kulmala, M., Riipinen, I., Wagner, R., Hussein, T., Aalto, P. P., and Lehtinen, K. E. J.: Formation and Growth of Fresh Atmospheric Aerosols: Eight Years of Aerosol Size Distribution Data from SMEAR II, Hyytiälä, Finland, Boreal Environ. Res., 10, 323-336, 2005.

Ehn, M., Junninen, H., Petäjä, T., Kurtén, T., Kerminen, V.-M., Schobesberger, S., Manninen, H. E., Ortega, I. K., Vehkamäki, H., Kulmala, M., and Worsnop, D. R.: Composition and temporal behavior of ambient ions in the boreal forest, Atmos. Chem. Phys., 10, 8513-8530, doi:10.5194/acp-10-8513-2010, 2010.

Ehn, M., Vuollekoski, H., Petäjä, T., Kerminen, V.-M., Vana, M., Aalto, P. P., de Leeuw, G., Ceburnis, D., Dupuy, R., O’Dowd, C. D., and Kulmala, M.: Growth rates during coastal and marine new particle formation in western Ireland, J. Geophys. Res., 115, D18218, doi:10.1029/2010JD014292, 2010b.

Gagné, S., Laakso, L., Petäjä, T., Kerminen, V.-M., and Kulmala, M.: Analysis of one year of Ion-DMPS data from the SMEAR II station, Finland, Tellus, 60B, 318-329, 2008.

Gagné, S., Nieminen, T., Kurtén, T., Manninen, H. E., Petäjä, T., Laakso, L., Kerminen, V.-M., Boy, M., and Kulmala, M.: Factors influencing the contribution of ion-induced nucleation in a boreal forest, Finland, Atmos. Chem. Phys., 10, 3743-3757, doi:10.5194/acp-10-3743-2010, 2010.

Hõrrak, U., Salm, J., and Tammet, H.: Bursts of intermediate ions in atmospheric air, J. Geophys. Res., 103, D12, 13909-13915, 1998.

Hari, P. and Kulmala, M.: Station for Measuring EcosystemAtmosphere Relations (SMEAR II), Boreal Env. Res., 10, 315322, 2005.

Hirsikko, A., Nieminen, T., Gagné, S., Lehtipalo, K., Manninen, H. E., Ehn, M., Hõrrak, U., Kerminen, V.-M., Laakso, L., McMurry, P. H., Mirme, A., Mirme, S., Petäjä, T., Tammet, H., Vakkari, V., Vana, M., and Kulmala, M.: Atmospheric ions and nucleation: a review of observations, Atmos. Chem. Phys., 11, 767798, doi:10.5194/acp-11-767-2011, 2011.

Hõrrak, U., Aalto, P. P., Salm, J., Komsaare, K., Tammet, H., Mäkelä, J. M., Laakso, L., and Kulmala, M.: Variation and balance of positive air ion concentrations in a boreal forest, Atmos. Chem. Phys., 8, 655-675, doi:10.5194/acp-8-655-2008, 2008.

Hoppel, W. A., and Frick, G. M.: Ion-aerosol attachment coefficients and the steady-state charge distribution on aerosol in a bipolar environment, Aerosol Sci. Technol., 5, 1-21, 1986.

Hussein, T., Martikainen, J., Junninen, H., Sogacheva, L., Wagner, R., Dal Maso, M., Riipinen, I., Aalto, P. P., and Kulmala, M.: Observation of regional new particle formation in the urban atmosphere, Tellus, 60B, 509-521, 2008. 
Iida, K., Stolzenburg, M. R., McMurry, P. H., Dunn, M. J., Smith, J. N., Eisele, F., and Keady, P.: Contribution of ion-induced nucleation to new particle formation: Methodology and its application to atmospheric observations in Boulder, Colorado, J. Geophys. Res., 111, d23201, doi:10.1029/2006JD007167, 2006.

Iida, K., Stolzenburg, M. R., McMurry, P. H., and Smith, J. N.: Estimating nanoparticle growth rates from sizedependent charged fractions: Analysis of new particle formation events in Mexico City, J. Geophys. Res., 113, d05207, doi:10.1029/2007JD009260, 2008.

Järvi, L., Hannuniemi, H., Hussein, T., Junninen, H., Aalto, P. P., Hillamo, R., Mäkelä, T., Keronen, P., Siivola, E., Vesala, T., and Kulmala, M.: The urban measurement station SMEAR III: Continuous monitoring of air pollution and surface-atmosphere interactions in Helsinki, Finland, Boreal Environ. Res., 14 (suppl. A), 86-109, d05207, doi:10.1029/2007JD009260, 2009.

Kazil, J., Lovejoy, E. R., Barth, M. C., and O'Brien, K.: Aerosol nucleation over oceans and the role of galactic cosmic rays, Atmos. Chem. Phys., 6, 4905-4924, doi:10.5194/acp-6-4905-2006, 2006.

Kerminen, V.-M. and Kulmala, M.: Analytical formulae connecting the "real" and the "apparent" nucleation rate and the nuclei number concentration for atmospheric nucleation events, J. Aerosol Sci., 33, 609-622, 2002.

Kerminen, V.-M., Anttila, T., Petäjä, T., Laakso, L., Gagné, S., Lehtinen, K. E. J., and Kulmala, M.: Charging state of the atmospheric nucleation mode: Implications for separating neutral and ion-induced nucleation, J. Geophys. Res., 112, d21205, doi:10.1029/2007JD008649, 2007.

Kerminen, V.-M., Petäjä, T., Manninen, H. E., Paasonen, P., Nieminen, T., Sipilä, M., Junninen, H., Ehn, M., Gagné, S., Laakso, L., Riipinen, I., Vehkamäki, H., Kurtén, T., Ortega, I., Dal Maso, M., Brus, D., Hyvärinen, A., Lihavainen, H., Leppä, J., Lehtinen, K. E. J., Mirme, A., Mirme, S., Hõrrak, U., Berndt, T., Stratmann, F., Birmili, W., Wiedensohler, A., Metzger, A., Dommen, J., Baltensperger, U., Kiendler-Scharr, A., Mentel, A., Wildt, J., Winkler, P., Wagner, P. E., Petzgold, A., Minikin, A., Plass-Dülmer, C., Pöschl, U., Laaksonen, A., and Kulmala, M.: Atmospheric nucleation: highlights of the EUCAARI project and future directions, Atmos. Chem. Phys., 10, 10829-10848, doi:10.5194/acp10-10829-2010, 2010.

Kulmala, M., Vehkamäki, H., Petäjä, T., Dal Maso, M., Lauri, A., Kerminen, V.-M., Birmili, W., and McMurry, P. H.: Formation and growth rates of ultrafine atmospheric particles: a review of observations, J. Aerosol Sci., 35, 143-176, 2004.

Kulmala, M., Riipinen, I., Sipilä, M., Manninen, H. E., Petäjä, T., Junninen, H., Dal Maso, M., Mordas, G., Mirme, A., Vana, M., Hirsikko, A., Laakso, L., Harrison, R. M., Hanson, I., Leung, C., Lehtinen, K. E. J., and Kerminen, V.: Toward direct measurement of atmospheric nucleation, Science, 318, 89-92, 2007.

Kulmala, M., Riipinen, I., Nieminen, T., Hulkkonen, M., Sogacheva, L., Manninen, H. E., Paasonen, P., Petäjä, T., Dal Maso, M., Aalto, P. P., Viljanen, A., Usoskin, I. Vainio, R., Mirme, S., Mirme, A., Minikin, A., Petzold, A., Hõrrak, U., Plass-Dülmer, C., Birmili, W., and Kerminen, V.-M.: Atmospheric data over a solar cycle: no connection between galactic cosmic rays and new particle formation, Atmos. Chem. Phys., 10, 1885-1898, doi:10.5194/acp-10-1885-2010, 2010.
Laakso, L., Petäjä, T., Lehtinen, K. E. J., Kulmala, M., Paatero, J., Hõrrak, U., Tammet, H., and Joutsensaari, J.: Ion production rate in a boreal forest based on ion, particle and radiation measurements, Atmos. Chem. Phys., 4, 1933-1943, doi:10.5194/acp-41933-2004, 2004.

Laakso, L., Gagné, S., Petäjä, T., Hirsikko, A., Aalto, P. P., Kulmala, M., and Kerminen, V.-M.: Detecting charging state of ultrafine particles: instrumental development and ambient measurements, Atmos. Chem. Phys., 7, 1333-1345, doi:10.5194/acp-71333-2007, 2007.

Laakso, L., Grönholm, T., Kulmala, L., Haapanala, S., Hirsikko, A., Lovejoy, E. R., Kazil, J., Kurtén, T., Boy, M., Nilsson, E. D., Sogachev, A., Riipinen, I., Stratmann, F., and Kulmala, M.: Hot-air balloon as a platform for boundary layer profile measurements during particle formation, Boreal Environ. Res., 12, 279-294, 2007b.

Laakso, L., Laakso, H., Aalto, P. P., Keronen, P., Petäjä, T., Nieminen, T., Pohja, T., Siivola, E., Kulmala, M., Kgabi, N., Molefe, M., Mabaso, D., Phalatse, D., Pienaar, K., and Kerminen, V.-M.: Basic characteristics of atmospheric particles, trace gases and meteorology in a relatively clean Southern African Savannah environment, Atmos. Chem. Phys., 8, 4823-4839, doi:10.5194/acp-8-4823-2008, 2008.

Lohmann, U. and Feichter, J.: Global indirect aerosol effects: a review, Atmos. Chem. Phys., 5, 715-737, doi:10.5194/acp-5-7152005, 2005.

Lovejoy, E. R., Curtius, J., and Froyd, K. D.: Atmospheric ioninduced nucleation of sulfuric acid and water, J. Geophys. Res., 109, D08204, doi:10.1029/2003JD004460, 2004.

Mäkelä, J. M., Salm, J., Smirnov, V. V., Koponen, I., Paatero, J., and Pronin, A. A.: Electrical charging state of fine and ultrafine particles in boreal forest air, J. Aerosol Sci., 32, S149-S150, 2003.

Manninen, H. E., Nieminen, T., Riipinen, I., Yli-Juuti, T., Gagné, S., Asmi, E., Aalto, P. P., Petäjä, T., Kerminen, V.-M., and Kulmala, M.: Charged and total particle formation and growth rates during EUCAARI 2007 campaign in Hyytiälä, Atmos. Chem. Phys., 9, 4077-4089, doi:10.5194/acp-9-4077-2009, 2009.

Manninen, H. E., Nieminen, T., Asmi, E., Gagné, S., Häkkinen, S., Lehtipalo, K., Aalto, P., Vana, M., Mirme, A., Mirme, S., Hõrrak, U., Plass-Dülmer, C., Stange, G., Kiss, G., Hoffer, A., Törö, N., Moerman, M., Henzing, B., de Leeuw, G., Brinkenberg, M., Kouvarakis, G. N., Bougiatioti, A., Mihalopoulos, N., O’Dowd, C., Ceburnis, D., Arneth, A., Svenningsson, B., Swietlicki, E., Tarozzi, L., Decesari, S., Facchini, M. C., Birmili, W., Sonntag, A., Wiedensohler, A., Boulon, J., Sellegri, K., Laj, P., Gysel, M., Bukowiecki, N., Weingartner, E., Wehrle, G., Laaksonen, A., Hamed, A., Joutsensaari, J., Petäjä, T., Kerminen, V.-M., and Kulmala, M.: EUCAARI ion spectrometer measurements at 12 European sites - analysis of new particle formation events, Atmos. Chem. Phys., 10, 7907-7927, doi:10.5194/acp-10-79072010, 2010.

Merikanto, J., Spracklen, D. V., Mann, G. W., Pickering, S. J., and Carslaw, K. S.: Impact of nucleation on global CCN, Atmos. Chem. Phys., 9, 8601-8616, doi:10.5194/acp-9-8601-2009, 2009.

Myhre, G., Berglen, T. F., Johnsrud, M., Hoyle, C. R., Berntsen, T. K., Christopher, S. A., Fahey, D. W., Isaksen, I. S. A., Jones, T. A., Kahn, R. A., Loeb, N., Quinn, P., Remer, L., Schwarz, J. P., and Yttri, K. E.: Modelled radiative forcing of the direct aerosol 
effect with multi-observation evaluation, Atmos. Chem. Phys., 9, 1365-1392, doi:10.5194/acp-9-1365-2009, 2009.

Pierce, J. R. and Adams, P. J.: Uncertainty in global CCN concentrations from uncertain aerosol nucleation and primary emission rates, Atmos. Chem. Phys., 9, 1339-1356, doi:10.5194/acp-91339-2009, 2009.

Spracklen, D. V., Carslaw, K. S., Kulmala, M., Kerminen, V.-M., Sihto, S.-L., Riipinen, I., Merikanto, J., Mann, G. W., Chipperfield, M. P., Wiedensohler, A., Birmili, W., and Lihavainen, H.: Contribution of particle formation to global cloud condensation nuclei concentrations, Geophys. Res. Lett., 35, L06, 808-812, 2008.

Stevens, B. and Feingold, G.: Untangling aerosol effects on clouds and precipitation in a buffered system, Nature, 461, 607-613, 2009.

Stolzenburg, M. R. and McMurry, P. H.: An ultrafine aerosol condensation nucleus counter, Aerosol Sci. Technol., 14, 48-65, 1991.

Svensmark, H., Pedersen, J. O., Marsh, N. D., Enghoff, M. B., and Uggerhøj, U. I.: Experimental evidence for the role of ions in particle nucleation under atmospheric conditions, Proc. R. Soc. A, 463, 385-396, 2007.

Tammet, H.: Continuous scanning of the mobility and size distribution of charged clusters and nanometer particles in atmospheric air and the Balanced Scanning Mobility Analyzer BSMA, Atmos. Res., 82, 523-535, 2006.

Twomey, S.: Aerosols, clouds and radiation, Atmos. Environ., 25A, 2435-2442, 1991.
Vana, M., Tamm, E., Hõrrak, U., Mirme, A., Tammet, H., Laakso, L., Aalto, P. P., and Kulmala, M.: Charging state of atmospheric nanoparticles during the nucleation burst events, Atmos. Res., 82, 536-546, 2006.

Wiedensohler, A.: An approximation of the bipolar charge distribution for particles in the submicron range, J. Aerosol Sci., 19, 387-389, 1988.

Winkler, P. M., Steiner, G., Virtala, A., Vehkamäki, H., Noppel, M., Lehtinen, K. E. J., Reischl, G. P., Wagner, P. E., and Kulmala, M.: Heterogeneous Nucleation Experiments Bridging the Scale from Molecular Ion Clusters to Nanoparticles, Science, 319, 1374 1377, doi:10.1126/science. 1149034, 2008.

Winklmayr, W., Reischl, G. P., Lindner, A. O., and Berner, A.: A new electromobility spectrometer for the measurement of aerosol size distributions in the size range from 1 to $1000 \mathrm{~nm}$, J. Aerosol Sci., 22, 289-296, 1991.

Yu, F.: From molecular clusters to nanoparticles: second-generation ion-mediated nucleation model, Atmos. Chem. Phys., 6, 51935211, doi:10.5194/acp-6-5193-2006, 2006.

$\mathrm{Yu}, \mathrm{F}$. I Ion-mediated nucleation in the atmosphere: Key controlling parameters, implications, and look-up table, J. Geophys. Res., 115, D03 206, doi:10.1029/2009JD012630, 2010.

Yu, F., Wang, Z., Luo, G., and Turco, R.: Ion-mediated nucleation as an important global source of tropospheric aerosols, Atmos. Chem. Phys., 8, 2537-2554, doi:10.5194/acp-8-2537-2008, 2008. 